\title{
Assessment of Serum Iron and Zinc Status in Febrile Seizures - A Prospective Case Control Study
}

\author{
Siddarth S Joshi
}

\section{Introduction}

Epilepsy is one of the most common disorders of the brain. ${ }^{1}$ One of every ten people will have at least one epileptic seizure during a normal lifespan, and a third of these will develop epilepsy. Worldwide, epilepsy affects 50 million people. According to a World Health Organization (WHO) survey, epilepsy accounts for $1 \%$ of the global burden of disease, a figure equivalent to breast cancer in women and lung cancer in men. ${ }^{2}$

Epilepsy has been known since antiquity. An Assyrian-Babylonian textbook written over three millennia ago provides an accurate clinical description of the condition, ${ }^{3}$ and Indian and Chinese physicians of that time were also familiar with it. The word epilepsy is derived from the Greek verb epilamvanein ("to be seized', 'to be taken hold of', or 'to be attacked').

This terminology derived from the very ancient notion that all diseases represented attacks by the gods or evil spirits, usually as punishment. Because seizures were the most vivid example of demonic possession, epilepsy was considered to be the sacred disease', and by the fifth century BC, the word had gradually acquired the specific and particular meaning associated with it today. ${ }^{4}$ Indeed, the battle between prejudice and acceptance, ignorance and knowledge, myth and science, and charlatanism and rational therapy has been long and difficult, and even today it has not yet been fully won. Hippocrates in about $400 \mathrm{BC}$ postulated that epilepsy is a disease of the brain that must be treated by diet and drugs, not religious incantations. ${ }^{5}$

Epilepsy is, of course, not a specific disease, or even a single syndrome, but rather a broad category of symptom complexes arising from any number of disordered brain ${ }^{3}$ functions that themselves may be secondary to a variety of pathologic processes.

The terms convulsive disorder, seizure disorder, and cerebral seizures are used synonymously with epilepsy: They all refer to recurrent paroxysmal episodes of brain dysfunction manifested by stereotyped alterations in behavior. ${ }^{1}$

Modern concepts of epilepsy originate in the work of mid-19th century physicians and scientists, the most important among them being John Hughlings Jackson. ${ }^{6}$ At a time when epilepsy denoted disorders manifested by generalized convulsions, which were believed to arise from disturbances in the medulla oblongata, Hughlings Jackson established the important concept that there were different categories of seizures, each with its own physiology and semiology. His explanation of 'dreamy states' and 'uncinate group of fits' as focal seizures originating from discrete areas within the cerebral cortex comes close to present-day views of limbic seizures. Similarly, his recognition of focal motor seizures ('Jacksonian seizures') not only identified the responsible locus within the brain, but also allowed him to draw inferences that have forever changed our concepts of cortical motor representation and cerebral control of voluntary movement. Hughlings Jackson, more than anyone, established a scientific approach to the study of epileptic phenomena.

There have been many attempts to obtain a consensus on definitions of epileptic seizure and epilepsy. Recently, the International League against Epilepsy (ILAE) has proposed new definitions for both. In this proposal, an epileptic seizure is defined as transient occurrence of signs and/or symptoms due to abnormal excessive or synchronous neuronal activity in the brain. This definition acknowledges that previous concepts of decreased inhibition and increased excitation were oversimplifications, because inhibition is actually increased in some forms of epilepsy where phasic inhibition is a central element in the primary epileptogenic abnormality.

An epileptic seizure can also be a natural response of the normal brain to transient disturbance in function and, therefore, not necessarily an indication of an epileptic disorder. Such seizures are often referred to as provoked, acute symptomatic, or reactive. This accounts for a greater incidence of seizures (about $7 \%$ by age 80 ) than epilepsy (nearly $3 \%$ ). Epilepsy is a group of neurologic conditions, the fundamental characteristics of which are recurrent, usually unprovoked, epileptic seizures.

A common operational definition of epilepsy is two or more unprovoked seizures occurring more than 24 hours apart. ${ }^{4}$ However, the new ILAE proposal ${ }^{7}$ offers a more fundamental definition of epilepsy: chronic condition of the brain characterized by an enduring propensity to generate epileptic seizures, and by the neurobiological, cognitive, psychological, and social consequences of this condition. This definition emphasizes the existence of a persistent intrinsic epileptogenic abnormality that is a property of the brain itself and thus present even when seizures are not occurring. This contrasts with seizures that are dependent upon acute insults or other conditions that transiently affect an otherwise normal brain. An intrinsic epileptogenic abnormality of 
the brain necessary for a diagnosis of epilepsy, however, can resolve spontaneously, as in some age-related idiopathic epilepsies that typically remit.

Studies done in developing countries ${ }^{7}$ reported an annual incidence of 30-47 per 100000 populations. $60 \%$ of the epilepsies begin in childhood and $85 \%$ of status epileptics occur in neonate and preschool children age group. ${ }^{9}$ Seizures lead to unrelenting muscular activity leading to anaerobic metabolism and tissue breakdown as well as increase the cerebral metabolic rate exceeding the oxygen and glucose supply to brain leading to brain ischaemic, and neuronal death. ${ }^{10}$

The International League Against Epilepsy (2009) defines a Febrile Seizure as a seizure occurring in childhood between 6 months and 6 years of age, associated with a fever more than $38^{\circ} \mathrm{C}$ (rectal temperature) not caused by an infection of the central nervous system, without previous neonatal seizures or a previous unprovoked seizure and not meeting criteria for other acute symptomatic seizures. Febrile seizures are characterized by their benign prognosis.

Febrile seizures are the most common cause of convulsions in children and a frequent cause of emergency hospital admissions. ${ }^{11,12,13}$ Between 2 and 5\% of children (more common in boys) in Europe and the United States experience at least one FS before the age of 5 years. ${ }^{11,12,13}$ Although earlier Indian studies suggested that up to $10 \%$ of children experience a febrile seizure, recent data indicate that the incidence rate in India is similar to western figures. . $^{14,15}$

The pathophysiology of febrile seizures remains unclear. It is generally believed that a FS is an agedependent response of the immature brain to fever. ${ }^{17}$ This postulation is supported by the fact that most $(80-85 \%)$ febrile seizures occur between 6 months and 3 years of age, with the peak incidence at 18 months. ${ }^{1,11}, 12$ Although the mechanism of this increased susceptibility is unclear, animal models suggest that there enhanced neuronal excitability during the is normal brain maturation.

Risk factors for a first febrile seizure have been studied in comparison to febrile controls without seizures. A higher temperature was a risk factor for febrile seizures in two studies ${ }^{16,17}$ and a history of febrile seizures in the immediate family was noted in another study. ${ }^{18}$ Low plasma ferritin, reflecting poor iron status, also increased the risk. When both febrile and afebrile children were used as controls, in addition to a family history of febrile seizures, neonatal discharge at 28 days or later, parental report of slow development, and day care attendance were also risk factors. ${ }^{19}$

Despite the abundance iron in the environment, iron deficiency is the most common nutritional deficiency in the western world and the most common cause for anemia worldwide. The iron status of infants and children is especially precarious because of exaggerated needs imposed by growth. The hematologic consequences of iron deficiency have understandably dominated the interest of those involved in child health, but there is increasing concern with the implication of iron deficiency for tissue other than erythron.

Iron containing tissue proteins of known biologic importance include myoglobin and enzymes involved with mitochondrial oxygen transport, DNA synthesis, catecholamine metabolism and detoxification.

The extent to which function sub served by these proteins are compromised by iron deficiency remains to be defined. Nevertheless, it is appropriate to view iron deficiency as a systematic nutritional disorder of which anemia is but one expression.

Zinc is a micronutrient that is essential for the normal functioning of the central nervous system. It is needed for synthesis of gamma-amino butyric acid, an inhibitory neurotransmitter, and complements the inhibitory effects of calcium on the excitatory N-methyl-D-aspartate. When a patient develops low levels of zinc, the N-methyl-D-aspartate receptors become activated and induce an epileptic discharge in children with high fevers.

The association between iron and Zinc deficiency in febrile seizures has been studied before without any conclusive reports and this study was done for further confirmation, study is intended to assess the serum Iron and zinc levels in patients with febrile seizure patients.

\section{Historical Perspectives}

Febrile seizures are a form of acute symptomatic seizures. Until the mid-19th century, febrile seizures were not recognized as distinct from other seizures. Before that time, infantile convulsions were thought to be the result of irritation of the central nervous system (CNS). Presumed causes included gastrointestinal irritation, teething, improper diet, and fever. Treatment was nonspecific and focused on relieving the symptoms ${ }^{30}$ By the mid-19th century, this began to change, and treatment was directed at underlying causes rather than symptoms. ${ }^{31}$

Beginning in the latter part of the 19th century, fever came to be regarded as a primary factor in producing infantile convulsions. This emphasis on fever may have been related to the introduction of the thermometer into clinical use around this time.

Throughout the late 19th and early 20th centuries, any infantile convulsion was considered to be serious and potentially fatal and the prognosis was not favorable. This was because of a failure to separate 
febrile from neonatal and other symptomatic seizures. By the turn of the century, as it was gradually understood that seizures were a symptom and not a disease, treatment of the underlying cause became important.

Unfortunately, very few effective treatments were available. In the mid- $20^{\text {th }}$ century, studies focused on febrile seizures were published by Lennox ${ }^{32}$ and Livingston. ${ }^{33}$ These investigators found that a benign outcome was predicted by onset between 1 and 3 years, generalized seizure of short duration, single or few episodes family history positive for febrile convulsions, male sex, and normal findings on the electroencephalogram (EEG). Increased likelihood of later epilepsy was associated with onset before 1 year of age, prolonged or partial convulsions, multiple seizures, abnormal birth history, and family history of epilepsy, female sex, and abnormal EEG findings. Subsequent studies have confirmed many of these factors as predictive, albeit not very accurate predictors.

By the 1970s, three large population-based studies had been published that demonstrated a much lower risk for epilepsy following febrile seizures than previously proposed. These studies had very similar results, and formed the foundation for our current understanding of febrile convulsions. In their study of 18,500 children, van den Berg found a $2 \%$ incidence of febrile seizures with a 3\% rate of later epilepsy. ${ }^{34}$ In 1976 , the National Institute of Neurological Disorders and Stroke (NINDS) Collaborative Perinatal Project, which followed 54,000 infants prospectively, found an incidence of almost $4 \%$ for febrile seizures. ${ }^{35}$

The developmental outcome was unaffected, and the overall incidence of later epilepsy was relatively small $(2 \%)$. Verity followed a British cohort of 14,676 children. ${ }^{36}$ The incidence of at least one febrile seizure was $2.7 \%$, and $2.3 \%$ of those

With febrile seizures later developed epilepsy.

\section{Definitions}

In 1980, the National Institutes of Health (NIH) Consensus Panel defined febrile seizures as "An event in infancy or early childhood, usually occurring between three months and five years of age, associated with fever but without evidence of intracranial infection or defined cause. Seizures with fever in children who have suffered a previous nonfebrile seizure are excluded. Febrile seizures are to be distinguished from epilepsy, which is characterized by recurrent nonfebrile seizures". ${ }^{37}$

This definition excludes any seizure that occurs in the presence of neurologic illness, such as encephalitis, meningitis, or toxic encephalopathy. The prognosis for such seizures is different from that of febrile seizures, because the underlying illnesses can potentially cause CNS sequelae. Seizures caused by mild encephalopathies may be included within this definition, such as those associated with Shigella, a bacterium that produces a neurotoxin.

Febrile seizures are difficult to define in malaria-endemic areas where all children are infected from time to time, many have elevated temperatures, and the severity of brain involvement is often measured by severity of the seizure disorder as well as level of consciousness.

Simple febrile seizures are those that last less than 15 minutes and are generalized. Complex febrile seizures are prolonged, multiple within 24 hours, or partial. Seizures in either of these subgroups may be accompanied by a pre-existing neurologic abnormality or a family history of either febrile or afebrile seizures. Although neurologically abnormal child are more likely to experience complex febrile seizures and have a higher risk of subsequent afebrile seizures, the child prior neurologic condition is not used to classify the seizure as simple or complex. When a careful history is obtained, approximately $30 \%$ of patients with febrile seizures presenting to emergency department are found to have complex features (Swaiman). ${ }^{39}$

Febrile status epilepticus follows the usual definition of 30 minutes of continuous or intermittent convulsive phenomena without the return of consciousness. Discussion remains about the age range used in the NIH Consensus Panel definition. Many experts feel that age between 3 and 6 months is rather young for the onset of a first febrile seizure. In fact, it may herald the onset of Dravet syndrome, a recently described epilepsy syndrome. As well, children have febrile seizures beyond the fifth birthday, and it has been suggested that the upper age limit be the sixth birthday. Another area of contention is a standard definition of "fever" and how a child's temperature should be measured (i.e., oral, rectal, axillary, or tympanic measurement). Based on the childhood vaccine trial literature, our definition of an elevated temperature is $38^{\circ} \mathrm{C}$ per rectum or $38.5^{\circ} \mathrm{C}$ orally. Although the increased temperature may not occur until after the seizure. ${ }^{39}$

Seizures are not considered to be "febrile seizures" when they occur with fever but in the context of exposure to proconvulsant drugs such as diphenhydramine, tricyclic antidepressants, amphetamines, and cocaine.

\section{Epidemiology}

In the United States, South America, and Western Europe, febrile seizures are experienced by $2 \%$ to $5 \%$ of all children before the age of 5 years. ${ }^{35,40}$ They are reported to be even more common in certain Asian countries. ${ }^{41,42}$ 
The first febrile seizure is complex (lasting more than 15 minutes, partial, or multiple within 24 hours) in about $30 \%$ to $40 \%$ of cases. ${ }^{43}$ The peak incidence is in the second year of life, with the average age of onset between 18 and 22 months. Febrile seizures are slightly more common in boys. Onset after the age of 7 years is uncommon. 39

Traditionally, it was thought that febrile seizures most commonly occur as the first sign of a febrile illness. More recent studies, however, found that only $21 \%$ of the children experienced there seizure either before or with in 1 hour of the onset of fever, $57 \%$ had a seizure after 1 to $24 \mathrm{hrs}$ of fever and $22 \%$ experienced their febrile seizure more than $24 \mathrm{hrs}$ after the onset of fever. ${ }^{39}$

Risk factors for a first febrile seizure have been studied in comparison to febrile controls without seizure.

\section{Predictive Factors In Febrile Seizures ${ }^{44}$ \\ For a first febrile seizure \\ 1. Family history of febrile seizures \\ 2. Low plasma ferritin level \\ 3. Slow development \\ 4. Day care \\ 5. Higher temperature \\ 6. Delayed neonatal discharge}

\section{For recurrences}

1. "Complex" first febrile seizures

2. Family history of febrile seizures

3. High number of febrile episodes

4. Low fever

5. Short duration of fever before seizure

\section{For epilepsy}

1. Young age at onset

2. Abnormal development before first seizure

3. Family history of epilepsy

A higher temperature was a risk factor for febrile seizures in two studies ${ }^{16,17}$ and a history of febrile seizures in the immediate family was noted in another study. ${ }^{18}$ Low plasma ferritin, reflecting poor iron status, also increased the risk. When both febrile and a febrile children were used as controls, in addition to a family history of febrile seizures, neonatal discharge at 28 days or later, parental report of slow development, and day care attendance were also risk factors. ${ }^{45}$

Approximately $40 \%$ of children with a first febrile seizure will experience one or more recurrences.

The risk of a second seizure after a first is about the same as a third febrile seizure after a second. Most recurrences $(75 \%)$ are within 1 year of the first febrile seizure. Four major risk factors for recurrence have been identified:

(a) A young age ( $<12-18$ months); ${ }^{43,46}$

(b) A family history of febrile seizures; ${ }^{17,45,47}$

(c) A low temperature at the time of seizure; ${ }^{48}$

(d) A short duration of fever before the first seizure. ${ }^{48}$

The recurrence risk for those with none of the four factors was $14 \%$, with one factor $23 \%$, with two $32 \%$, with three $62 \%$, and with all four $76 \%{ }^{49}$ In a meta-analysis, young age of onset and a family history of febrile convulsions were the strongest predictors of recurrence ${ }^{50}$ (see Table 1). A family history of a febrile

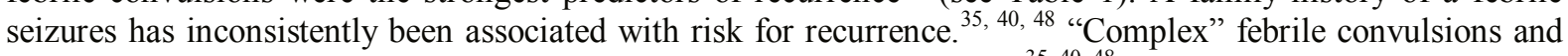
neurologic dysfunction do not influence the chance of febrile recurrences. ${ }^{35,40,48}$

\section{Genetics $^{44}$}

There is an important genetic predisposition for febrile seizures, and genetic factors exist that may be either causative or protective. It is natural to consider the possibility of a genetic propensity for the occurrence of a febrile seizure; however there may also be protective gene(s) in those who never experience a febrile seizure. These protective gene(s) might raise the seizure threshold.

Although the exact mode of inheritance is not known, febrile seizures tend to run in families. An autosomal recessive mode of inheritance is not likely, because there is an excess of affected parents and the risk to siblings is less than $25 \%$. A polygenic mode of inheritance or dominance with incomplete penetrance is more 
likely. ${ }^{51,52}$ afebrile seizures or epilepsy may be more common in families of children with febrile seizures, but the evidence is controversial.

When a child has a first febrile seizure, the risk for younger siblings is in the range of $10 \%$ to $20 \%$ and even higher if a parent reports having had a febrile convulsion. ${ }^{53}$

Two unique epilepsy syndromes always include seizures with fever: generalized epilepsy with febrile seizures plus (GEFS+) and Dravet syndrome (severe myoclonic epilepsy of infancy). ${ }^{54}$ GEFS+ is an autosomal dominant epilepsy syndrome with $80 \%$ penetrance and is associated with heterogeneous clinical phenotypes. ${ }^{55}$

In a given family, about one third of those affected have one or more febrile seizures that often persist beyond the usual age of 5 years. About one third have febrile seizures and then afebrile generalized tonic-clonic seizures in adolescence that usually remit. A final third have other epilepsy syndromes, usually, but not always, generalized syndromes (myoclonic-astatic epilepsy, typical childhood absence, and even Dravet syndrome). Several gene mutations have been identified involving voltage-gated sodium channels of SCN1A and the $\gamma 2$ subunit of ligated- $\gamma$-amino butyric acid (GABA)-2 receptor..$^{55}$ Dravet syndrome begins in the first year of life with prolonged, often unilateral febrile seizures precipitated by relatively low-grade fever. Development stagnates or regresses around 1 year of age, when other seizure types develop (myoclonic, atypical absence, or partial). Ataxia and important behavior problems (hyperactivity) are very common. Dravet syndrome may occur within families with GEFS+ and with the identical gene defect, but in approximately $50 \%$ of cases, no de novo missense or truncating mutations of the SCN1A subunit are present. ${ }^{55}$ The complete genetic story of febrile seizures is still incomplete. More than seven chromosome linkage sites have been associated with febrile seizures, suggesting locus heterogeneity. In addition, at least five genes have been identified as causal for epilepsy syndromes that include febrile seizures, including GEFS+. These findings may provide insights into the biology of age-limited temperature-dependent seizure susceptibility.

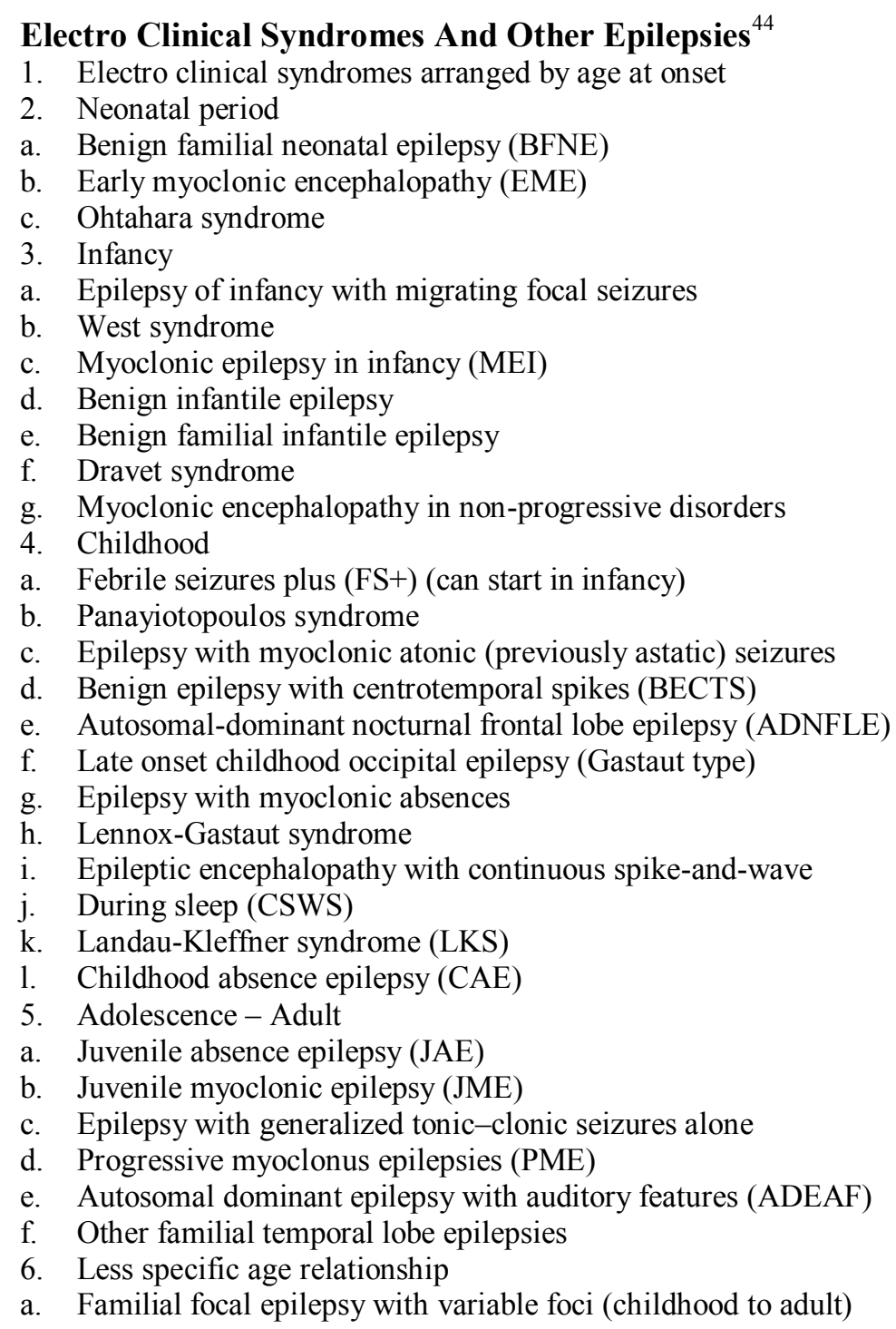


b. Reflex epilepsies

7. Distinctive constellations

a. Mesial temporal lobe epilepsy with hippocampal

b. Sclerosis (MTLE with HS)

c. Rasmussen syndrome

d. Gelastic seizures with hypothalamic hamartoma

e. Hemi convulsion-hemiplegic-epilepsy

Epilepsies that do not fit into any of these diagnostic categories can be distinguished first on the basis of the presence or absence of a known structural or metabolic condition (presumed cause) and then on the basis of the primary mode of seizure onset (generalized vs. focal).

Epilepsies attributed to and organized by structural-metabolic causes

1. Malformations of cortical development (hemimegalencephaly, heterotopias, etc.)

2. Neurocutaneous syndromes (tuberous sclerosis complex, Sturge-Weber, etc.)

3. Tumor Infection

4. Trauma

5. Angioma

6. Perinatal insults

7. Stroke

8. etc.

Epilepsies of unknown cause

Conditions with epileptic seizures that are traditionally not diagnosed as a form of epilepsy per se

Benign neonatal seizures (BNS)

Febrile seizures (FS)

\section{Etiology And Basic Mechanisms ${ }^{44}$}

"Everyday" infections, such as tonsillitis, upper respiratory infections, otitis media, roseola infantum, or Shigella gastroenteritis are often implicated as the cause of fever in children with febrile seizures. Unfortunately, there are no recent studies of the epidemiology of these infections, since vaccines against Haemophilus influenzae, Varicella, Pneumococcus, Meningococcal and influenza are in widespread use and have likely changed the panorama of childhood febrile illness.

Seizures occurring soon after immunization with whole-cell Diphtheria pertussis-tetanus (DPT) and measles vaccines should not be regarded as a direct adverse effect of the vaccine.56 Such seizures are believed to be "ordinary febrile seizures" triggered by fever induced by the vaccine. Their subsequent clinical course is identical to other febrile seizures, 57 with no increased risk for subsequent afebrile seizures or abnormal neurologic development.58 The frequency of febrile seizures after DPT or measles vaccination is six to nine, and 24 to 25 per 100,000 children vaccinated, respectively. Newer acellular pertussis vaccines rarely induce a febrile reaction and, since their introduction in Canada, there has been a 79\% decrease in hospital admissions for DPT vaccine related febrile seizures. ${ }^{59}$

The patho physiology of febrile seizures is unknown. The role of activation of the cytokine network is presently being studied. There appears to be increased susceptibility to febrile seizures associated with specific interleukin alleles. ${ }^{60,61,62,63}$

Circulating toxins, immune reaction products, and viral or bacterial invasion of the CNS have been implicated, together with relative lack of myelination in the immature brain and increased oxygen consumption during the febrile episode. ${ }^{54}$

Immaturity of thermoregulation and a limited capacity to increase cellular energy metabolism at elevated temperatures have been suggested as contributory factors. ${ }^{65}$

Recent reports indicate that human herpes virus type 6 (HHV6), which causes roseola, is strongly associated with febrile seizures. ${ }^{38}$ HHV6 infection was identified in eight of 42 children with a first febrile seizure ${ }^{67}$ In children with multiple febrile seizures, HHV-6 DNA was detected in the cerebrospinal fluid, but not in controls without febrile seizures.

It was postulated that viral invasion of the brain might occur during roseola, with reactivation by fever during subsequent illnesses, thus provoking recurrent febrile seizures. In a survey of general practitioners throughout the Netherlands, a significant relationship was noted between recurrent febrile seizures and influenza A; therefore, vaccination against influenza A may be considered after a first febrile seizure as a strategy to reduce the risk of recurrences.

GABA is the predominant inhibitory neurotransmitter in the adult brain and plays a critical role in the regulation of excitability of neuronal networks. ${ }^{69} \mathrm{GABA}$ binding to inotropic GABA 'A' receptors opens the receptor ionophore, which is permeable to $\mathrm{Cl}^{\text {' }}$ and, to a lesser extent, to $\mathrm{HCO}$. In the presence of a normal adult trans membranous $\mathrm{Cl}$ - gradient, this results in expression of an inhibitory postsynaptic current that 
hyperpolarizes the postsynaptic neuronal membrane. GABA 'A' receptor mediated synaptic currents have been studied in human hippocampal neurons from epilepsy patients. ${ }^{70,71}$ These studies have revealed a significantly higher sensitivity of human GABA 'A' receptors to zinc, a finding also observed in chronic epilepsy animal models.

Increased zinc sensitivity of GABA ' $A$ ' receptors is thought to render them susceptible to blockade by zinc released from recurrent mossy fibers during seizures, potentially causing a breakdown of dentate inhibition. ${ }^{69}$ Studies of mRNA expression for different GABA ' $A$ ' receptor subunits and correlation with physiologic and pharmacologic properties suggest that GABA ' $A$ ' receptors are regulated in a coordinate fashion in human hippocampal neurons. ${ }^{72}$ The epilepsy-associated regulation of GABA 'A' receptor subunits has been addressed using immunohistochemistry and in situ hybridization in hippocampal sclerosis. ${ }^{73,74}$ Apart from changes in GABA receptors, GABAergic neurotransmission is also influenced by changes in the transmembrane chloride gradient. Indeed, GABA ' $A$ ' receptor activation becomes depolarizing because of altered chloride homeostasis in a subset of subicular neurons in human epilepsy. ${ }^{75,76}$ GABAergic inhibitory postsynaptic potentials are governed by the time course with which GABA is removed from the synaptic cleft.

This task is sub served by GABA transporters, which may be impaired in the human dentate gyrus. ${ }^{77}$ The molecular substrate for this phenomenon may be down regulation of the underlying transporter proteins. ${ }^{78,79}$ Impaired uptake of GABA may underlie prolonged GABA ' $\mathrm{A}$ '-mediated responses in hippocampal sclerosis. 80 Metabotropic GABA 'B' receptors inhibit neurotransmitter release from presynaptic terminals and mediate the late inhibitory postsynaptic potential. The expression of GABA ' $\mathrm{B}$ ' receptors has been examined in human temporal lobe epilepsy using various approaches, including in situ hybridization, immunohistochemistry, and ligand labeling. ${ }^{81}$ Given the significant changes in synaptic properties as well as the profound changes in $\mathrm{Ca} 2+$ dynamics and handling, it is not surprising that synaptic plasticity is greatly impaired in hippocampal sclerosis.

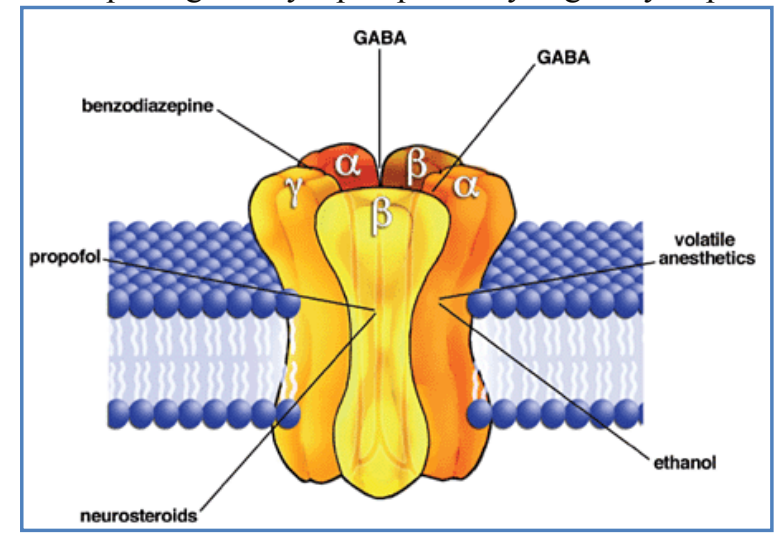

Figure 1: GABA 'B' receptors

Anemia:

Anemia is defined as a reduction of the red blood cell (RBC) volume or hemoglobin concentration below the range of values occurring in healthy persons (less than $2 \mathrm{SD}$ ). Anemia resulting from lack of sufficient iron for synthesis of hemoglobin is the most common hematologic disease of infancy and childhood. It is estimated that $30 \%$ of the global population suffers from iron-deficiency anemia; most of those affected live in developing countries.

The definition of anemia varies by sex and age. The most commonly used definitions of anemia come from the Centers for Disease Control and Prevention (CDC) and the World Health Organization (WHO). ${ }^{82,83}$

\begin{tabular}{|c|c|}
\hline Infants 0.5 to 4.9 years & $<11 \mathrm{~g} / \mathrm{dL}(110 \mathrm{~g} / \mathrm{L})$ \\
\hline Children 5.0 to 11.9 years & $<11.5 \mathrm{~g} / \mathrm{dL}(115 \mathrm{~g} / \mathrm{L})$ \\
\hline
\end{tabular}

Iron deficiency remains a major nutritional problem among infants and young children in India and is a leading cause of morbidity and mortality worldwide. ${ }^{1,2}$ Iron deficiencies was detected in $9 \%$ of infants and toddlers, with anemia in approximately one-third of those children. In infancy, the occurrence of iron deficiency is equal in both sexes. The National Family Health Survey III, ${ }^{84}$ documented that about 78.9 percent children between the ages of 6-35 months were anemic. This includes $26 \%$ who are mild anemic, $40 \%$ are moderately anemic and $3 \%$ suffer from severe anemia. ${ }^{84}$ The prevalence of iron deficiency is also higher among people living in chronic poverty. Iron deficiency tends to run in families, possibly as a result of economic factors. Adolescents are also susceptible to iron deficiency because of high requirements due to the growth spurt, dietary deficiencies, and menstrual blood loss. Numerous studies have demonstrated that even moderate anemia (hemoglobin $<10 \mathrm{gm} / \mathrm{dl}$ ) is associated with depressed mental and motor development in children that may not be reversible. 
Its frequency is related to certain basic aspects of iron metabolism and nutrition. The body of a newborn infant contains about $0.5 \mathrm{~g}$ of iron, whereas the adult content is estimated at $5 \mathrm{~g}$. To make up for this discrepancy, an average of $0.8 \mathrm{mg}$ of iron must be absorbed each day during the first 15 year of life. In addition to this growth requirement, a small amount is necessary to balance normal losses of iron by shedding of cells. Accordingly, to maintain positive iron balance in childhood, about $1 \mathrm{mg}$ of iron must be absorbed each day. ${ }^{2}$ Iron deficiency has been identified as the risk factor for first febrile seizure.

Iron lacks the glitter of gold and sparkle of silver but outshines both in biologic importance. This plebeian metal is vital to the function of a wide variety of critical enzymes, including catalases, aconitase, ribonucleotide reductase, peroxidases and cytochromes that exploit the flexible redox chemistry of iron to execute a number of chemical reactions essential for survival. In addition, we depend on hemoglobin, another iron containing protein, to transport inhaled oxygen from the lung to peripheral tissues. ${ }^{85}$

The key to the biologic utility of iron is its ability to exist in either of two stable oxidation states: ferrous $(\mathrm{Fe} 2+)$ or ferric $(\mathrm{Fe} 3+)$. This property permits iron to act as redox catalyst by reversibly donating or accepting electrons. When dissolved in aqueous solution, ferrous iron rapidly oxidizes to its ferric form, which is insoluble at physiologic $\mathrm{pH}^{85}$ The resulting ferric hydroxide salts (rust) are of no metabolic utility. To achieve stable solubility under physiologic conditions, iron must be complexed to iron binding agents termed chelators. Chelators are synthesized by all organisms ranging from microbes to humans. These molecules are crucial to the acquisition of iron from the environment and to its transport and storage within the body. ${ }^{85,86}$

\section{Iron Absorption}

Iron metabolism is unique in that iron balance is achieved by control of absorption rather than by control of excretion. ${ }^{85}$ Except for menstruation and child bearing, there is no physiological mechanism for substantive iron loss. In normal men and non-menstruating women, iron is lost only with the desquamation of epithelial cells from the skin, gut and urinary tract.

The loss of iron must be balanced by absorption of iron from the diet to maintain iron homeostasis. The amount of iron absorption is a function of the iron content of the diet, the bioavailability of dietary iron and the control exerted by intestinal mucosal cells.

Dietary iron: Absorption of 5\% to $10 \%(0.5-1 \mathrm{mg}$ iron) dietary iron can maintain iron balance in men. This proportion increases to $20 \%$ in iron deficiency, giving a maximal daily gain of 3 to $4 \mathrm{mg}$. In iron overload, there will be decreased iron absorption. ${ }^{85}$

There are two distinct pathway for iron absorption are for heme iron derived myoglobin and hemoglobin, and one for iron salt derived for the most part from non-animal sources. ${ }^{86}$

Factors Affecting The Bioavailability Of Dietary Nonheme Iron $^{86}$

\begin{tabular}{|c|c|}
\hline Enhance & Inhibit \\
\hline Ascorbic acid (Vit. C) & Tannates (tea, coffee) \\
\hline Meat Bran & Calcium \\
\hline Fish Egg yolk & EDTA \\
\hline Poultry & Antacids \\
\hline & Cholentyramine \\
\hline & Clay \\
\cline { 2 - 2 } & Starch \\
\cline { 2 - 2 }
\end{tabular}

In the final analysis, the dietary content of heme iron is far greater significance for iron balance than is the presence of factor that interferes with the bioavailability of non-heme iron. Absorption of non-heme iron from the diet is limited and erratic, whereas heme iron is well-absorbed and augments the absorption of nonheme iron.

It has been estimated that a meal containing both meat and ascorbic iron has four times as much available iron as one containing little of either, even though the diets are comparable with respect to iron, protein and calorie content. Thus, iron deficiency has its highest prevalence in countries where little or no meat is consumed.

\section{Acquisition And Distribution Of Iron}

Iron is absorbed in the proximal small intestine, mediated in part by a variety of duodenal proteins. ${ }^{2}$ Because absorption of dietary iron is assumed to be about $10 \%$, a diet containing $8-10 \mathrm{mg}$ of iron daily is necessary for optimal nutrition. Iron is absorbed two to three times more efficiently from human milk than from cow's milk, perhaps partly because of differences in calcium content. Breast-fed infants may, therefore, require less iron from other foods. ${ }^{2}$

During the first years of life, because relatively small quantities of iron-rich foods are eaten, it is often difficult to attain sufficient iron. For this reason, the diet should include such foods as infant cereals or formulas 
that have been fortified with iron; both of these are very effective in preventing iron deficiency. ${ }^{2}$ Formulas with $7-12 \mathrm{mg} \mathrm{Fe} / \mathrm{L}$ for full-term infants and premature infant formulas with $15 \mathrm{mg} / \mathrm{L}$ for infants less than $1,800 \mathrm{~g}$ at birth are effective. Infants breast-fed exclusively should receive iron supplementation from 4 month of age. ${ }^{2}$

Iron is absorption predominantly in the proximal duodenum. ${ }^{89}$ The physical state of iron entering the duodenum greatly influence its absorption. At physiological $\mathrm{pH}$, ferrous iron is rapidly converted to insoluble ferric form. Acid produced by the stomach serves to lower the $\mathrm{pH}$ and thereby enhance the solubility and uptake of iron.

Heme is absorbed separately from the more efficiently than inorganic iron, independent of duodenal $\mathrm{pH}$. Consequently, meat is an excellent nutritive source of iron. Heme iron absorption is poorly understood, but a heme oygenase inhibitor has been shown to block heme catabolism in the intestine and result in iron deficient state. $^{90}$

A number of dietary factors influence iron absorption. ${ }^{91}$ Ascorbate and citrate increase iron uptake, in part by acting as weak chealtors to help solubilize the metal in the duodenum. Iron is readily transferred from these compounds to the absorptive epithelium. Conversely, plant phytates, bran and tannins inhibit iron absorption. ${ }^{92,93}$ These compounds also chelate iron but prevent its uptake by the absorption machinery.

Non-heme iron arrives at the apical surface of the absorptive duodenal enterocyte in its ferric $(\mathrm{Fe} 3+)$ form. It is reduced through the action of a brush border ferric reductase. This enzyme may be duodenal cytochrome b, a heme protein that is homologous to b561 cytochromes. ${ }^{94}$ Expression of duodenal cytochrome B is significantly greater in the proximal duodenum than elsewhere and increases in iron deficiency.

Ferrous iron is then taken up by the enterocyte through the action of divalent metal transported 1 (DMT1). ${ }^{95,96}$ Transport requires movement of protons along with the metal ions (symport) to generate electrical gradient. DMT1 functions only at low pH; it has little or no activity at neutral pH. DMT1 is widely expressed, but duodenal levels increase dramatically in iron deficient state. ${ }^{96,97}$

DMT1 can also transport other divalent metal ions, including cadmium $(\mathrm{Cd} 2+)$, cobalt $(\mathrm{Co} 2+)$, copper $(\mathrm{Cu} 2+)$, manganese $(\mathrm{Mn} 2+)$, lead $(\mathrm{Pb} 3+) .{ }^{96}$ Increased iron absorption induced by iron deficiency also enhances the uptake of these elements.

Because iron deficiency often coexists with lead intoxication, this interaction has vast public importance and can produce particularly serious medical complication in children. ${ }^{98}$

After iron enters the absorptive enterocyte through the action of DMT1, it has at least two possible fates. It can be retained by the cell and subsequently be lost when the enterocyte dies and is sloughed into the intestinal lumen, or it can be transported across the basolateral membrane to enter the body. Iron retained by the enterocyte is used for cellular metabolism or incorporated into ferritin. Exported iron leaves the cell through the action of unique basolateral transmembrane iron transporter ferroprotein (FPN1, also known as SLC40A1, MTP IREG1). ${ }^{99,100,101}$

Basolateral iron transfer also requires a change in the oxidation state of the metal, probably mediated by the multicopper ferroxidase hepaestin, ${ }^{103,105}$ which bears strong homology to the plasma protein ceruloplasmin. A candidate intestinal heme transporter was reported but subsequently proven to be a folate transported instead. ${ }^{107}$

Normally, only $10 \%$ of dietary non heme iron entering the duodenum is absorbed. However, this value increases significantly with iron deficiency. ${ }^{105}$ In contrast; iron overload reduces, but does not completely eliminate absorption, thus reaffirming the fact that body iron stores regulate absorption. Investigation has designated this modulation the "stores regulator". ${ }^{105}$ In addition, both iron deficiency anemia and the anemia associated with ineffective erythropoesis induce a marked increase in iron absorption. This effect is greater than that seen with variations in iron stores, and it has been designated the "erythroid regulator". ${ }^{105}$ Additionally, hypoxia increases iron absorption, independent of anemia.

The peptide hormone hepcidin inks the actions of all these regulator through a unifying molecular mechanism. Hepcidin is a 25 -aminoacid pepride produced in the liver from a larger precursor. It circulates in serum and binds to iron exporter ferroprotein on the basolateral surface of absorptive enterocyte, which causes ferroprotein to be internalized and degraded. ${ }^{107}$ In this way, hepcidin controls cellular iron egress. Hepcidin thus regulates iron absorption at the level of intestinal epithelium in that any iron unable to leave the enterocytes is lost when these cells senesce and are sloughed into the gut lumen.

Expression of hepcidin is induced in response to iron overload ${ }^{108,109}$ and inflammation ${ }^{110,114}$ and repressed to increased erythropoietic activity ${ }^{111,112}$ and hypoxia. ${ }^{111}$ Regulation appears to be at the level of gene transcription. However, the signals that govern hepcidin transcription in response to these stimuli are incompletely understood. Only the inflammatory cytokines interleukin-6 has been definitely shown to be involved in regulation of hepcidin expression by physiologic changes outside the liver. ${ }^{13,114,115}$

Most of the total body iron is ultimately incorporated into hemoglobin in erythroid precursors. Recycle of iron from senescent red cells has crucial role to meet the demand of high red cells turnover. Plasma iron turnover (PIT) represents the mass turnover of transferring bound iron in the circulation. ${ }^{116}$ Accelerated 
erytropoiesis increases PIT and enhances iron uptake from the gastrointestinal tract. ${ }^{117}$ Although hepcidin appears to be the effector molecule that alters intestinal absorption, an upstream, circulating factor that communicates the iron needs or the erythron must exist. ${ }^{105,118}$

The erythroid control of hepcidin expression is particularly apparent in patients with thalaseemia intermedia, in whom marked iron overload develops even without transfusions. The accelerated but ineffective erythropoieses takes place in thalassemia substantially boosts iron absorption. Increased PIT also leads to increased gastrointestinal iron absorption in pregnancy, in which PIT is accelerated by placental removal of iron. This increases the availability of the element to meet the needs of growing and developing infant.

\section{Intracellular Iron Transport}

Only a small proportion of total body iron enters and leaves the body each day. Intracellular iron transport is quantitatively more important that intestinal absorption. The erythroid cells makes up 60 to $80 \%$ of the total body endowment in normal individuals.

Approximately $0.1 \%$ of total body iron circulates in plasma as an exchange pool. In normal individuals, nearly all circulating plasma iron is bound to transferring. Transferrin serves three purposes:

I. It renders iron soluble under physiological conditions

II. II. It prevents iron mediated free radical toxicity

III. It facilitates transport into cells

Transferrin is by far the most important physiologic supplier of iron to most tissues in the body. It is an 80-kd glycoprotein that has homologous N-terminal and C-terminal iron binding domains. The liver is the major site of synthesis and secretion of transferrin. Other tissues including sertoli cells of the testis, oligodendrocytes of central nervous system, lymphocytes muscles cells, and mammary cells can however also produce the protein.

Transferrin m RNA and protein have been detected in oligodendocytes. The blood brain barrier limits the access of central nervous system to serum molecules Iron is needed to support a vast array of redox reactions that produce specialized neurotransmitter compounds such as gamma aminobutyric acid which is an important inhibitoty neurotransmitter present in the central nervous system.

At other site such as Sertoli cells of testis transferrin play a vital role in spermatocyte development, and transferrin play a role in T lymphocyte mediated immunity.

The sum of all iron binding sites on transferrin constitutes the total iron binding capacity (TIBC) of plasma. This, on a molar basis, TIBC is twice the concentration of transferrin protein because each transferrin molecule can bind to two iron atoms. Under normal circumstances, about a third of transferrin's iron binding pockets are filled. Consequently, expect for the situation of iron over-load in which all transferrin bound iron in the circulation is present at very low concentrations.

Radioactive tracer studies indicate that at least $80 \%$ of the iron bound to circulating transferrin is delivered to the bone marrow and incorporated into newly formed reticulocytes.119,120 Other major sites of iron delivery include the liver, which is a primary depot of stored iron and the spleen. Hepatic iron is found both in the hepatocytes and reticuloendothelial cells. Aged red cells are broken down in the reticuloendothelial cells and iron extracted from heme is returned to circulation bound to transferrin.

Iron is taken into cells by receptor mediated endocytosis by diferric transferrin. ${ }^{121,122,123}$ Receptors on the outer surface of the plasma membrane bind iron on the outer plasma membrane bind loaded transferrin with very high affinity. The C-terminal domain of transferrin appears to mediate receptor binding. ${ }^{124}$ Diferric transferrin binds with much higher affinity than monoferric transferrin or apotransferrin. ${ }^{125,126}$ The cellular transferrin receptors are ordinarily fully saturated.

After binding to its receptors on the cell surface, transferrin is internalized through a constitutive mechanism that begins with invagination of clathrin coated pits and the formation of endocytic vesicles. This process requires the short, 61-aminoacid intracellular tail of the transferrin receptor molecule.127-129 Receptors truncated N-terminal cytoplasmic domains do not recycle properly. This portion of the molecule contains a conserved tyrosine-threonine-arginine-phenyalanine (YTRF) sequence that function as a signal for endocytosis. Genetically engineered addition of a second YTRF sequence enhances receptor endocytosis.

An ATP-dependent proton pump lowers the $\mathrm{pH}$ of the internalized endosome to about 5.5. ${ }^{130,131,132}$ Acidification of the endosomes weakens the association between iron and transferrin and promotes a conformational change in the transferrin receptor and facilitates release of iron.

An endosomal ferrrireductase must reduce iron from the ferric salt to ferrous salt, either at the same time that it is released from transferrin or soon afterwards.

The iron released from the transferrin must leave the endosomes and enter the cytoplasm and mitochondria for use in heme biosynthesis, $\mathrm{Fe} / \mathrm{S}$ cluster formation storage and other purpose. This transmembrane transport step is also mediated by DMT $1 .{ }^{133}$ Once transported out of the endosomes or across the 
plasma membrane, iron must be delivered to sites of use or stored in the form of ferritin. In the erythroid cells, iron is delivered across the mitochondrial inner membrane by mitoferrin-1 (SLC25A37), ${ }^{134}$ where it is incorporated into heme by the enzyme ferrochelatase Preservation and reuse of transferrin are accomplished by $\mathrm{pH}$ dependent changes in the affinity of transferrin for its receptor. ${ }^{122,}{ }^{124,129}$ The average transferrin molecule, with a half-life of 8 days, may be used hundreds of times for delivery of iron. The uptake of iron bound to transferrin is important for red blood cell hemoglobinization and maturation and for developing central nervous system. Lack of transferrin receptor leads to severe anemia and primitive neuroepithelial cell undergo apoptosis at greatly increased rate. Thus it can be concluded that transferring cycle is of primary importance in erythropoieses and neurogenesis but of lesser importance in other mammalian tissues.

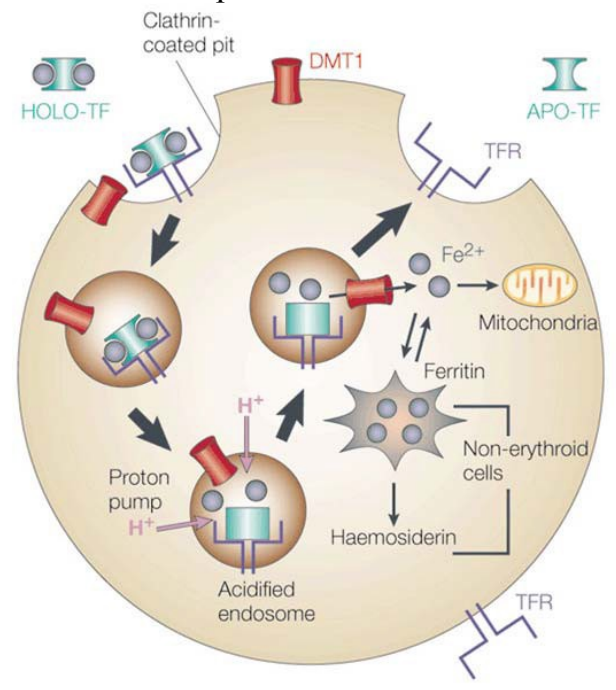

Figure 2: Fate of iron inside a cell

\section{The Endocytic Transferrin Cycle Ferritin}

Once inside the cytoplasm, iron is probably bound by unidentified carrier molecule that may assist in delivery to various intracellular locations, including mitochondria (for heme biosynthesis) and ferritin (for storage). The amount of iron in transit within the cell at any point of time is small and difficult to measure. This minute pool of transit iron, which is believed to be in the Fe2+ oxidation state, is biologically active and potentially toxic form of the element. Metabolically inactive iron, stored in ferritin and hemosiderin, is nontoxic and in equilibrium with this exchangeable transit iron.

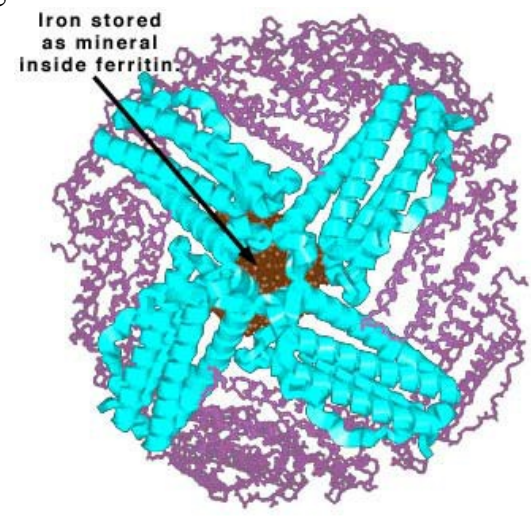

Figure 3: Structure of ferritin

Both prokaryotes and eukaryotes produce ferritin molecules for iron storage. Mammalian ferritin molecules are complex 24-subunit heteropolymers of $\mathrm{H}$ (for heavy or heart) and L (for light or liver) protein subunits. L subunit are $19.7 \mathrm{kd}$ in mass, with isoelectric points of 4.5 to $5.0 ; \mathrm{H}$ subunit are $21 \mathrm{kd}$ in mass with isoelectric points of 5.0 to 5.7 . The degree of homology between the two is only $50 \%$. They assemble to form a sphere with a central cavity in which up to several thousand atoms of crystal-line iron can be stored in the form of poly-iron-phosphateoxide. ${ }^{180}$ Eight channel through the sphere are lined by hydrophilic amino acid residues (along the three fold axes of symmetry) and six more are lined by hydrophobic residues (along the four fold axes). ${ }^{136}$ Strong interspecies amino acid conservation is seen in the residues that line the hydrophilic channels, 
whereas marked variation is seen in those along the hydrophobic passages. The hydrophilic channels terminate with aspartic acid and glutamic acid residues and are lined by serine, histidine, and cysteine residues.

Only $\mathrm{H}$ ferritin has ferroxidase activity. A mechanism involving dioxygen converts ferrous to ferric iron, thereby promoting incorporation into ferritin. ${ }^{137,}{ }^{138}$ The composition of ferritin shells varies from H-subunit homopolymers to L-subunit homopolymers and includes all possible combination between the two. Ferritin from liver and spleen is rich in L subunits and heart has ferritin rich in $\mathrm{H}$ subunit. Increased $\mathrm{H}$-subunit content correlates with increased iron utilization, whereas increased L-subunit content correlates with increased iron storage. ${ }^{139}$ The H-to-L ratio increases with increased cell proliferation. ${ }^{140}$ Thus ferritin provides a flexible reserve for iron.

Ferritin molecules aggregate into clusters that are engulfed by lysosomes and degraded. The end product of this process, hemosiderin, is an amorphous agglomerate of denatured protein and lipid interspersed with iron oxide molecules. In cells overloaded with iron, lysosomes accumulate large amount of hemosiderin, which can be visualized by Prussian blue staining. Hemosiderin is in equilibrium with soluble ferritin and ferritin iron is turn is in equilibrium with iron complexed with low molecular-weight carrier molecules. The bioavailability of hemosiderin iron is much lower than that of iron stored in ferritin.

The ferritin genes for $\mathrm{H}$ and L subunit are located in human chromosomes 11 and 19, respectively. In addition, there is an intronless gene encoding a mitochondrion specific H-like ferritin molecule located in human chromosome $5 q$.

Ferritin formation is controlled at multiple levels - transcription, message stabilization, translation and subunit assembly. In the liver and in HeLa cells, iron rapidly induces the synthesis of L subunit $m$ RNA, with no effect on H-subunit mRNA. Iron, heme, reactive oxygen species, and oxidative stress all enhance transcription and translation of the ferritin $\mathrm{H}$-subunit.

Cytoplasmic ferritin mRNA forms a stable complex with several proteins. Both iron and interleukin-1 $\beta$ enhance translation of ferritin mRNA. Influx of iron enhances the synthesis of ferritin subunits. This translation control mechanism involves an RNA protein interaction that links the expression of genes coding ferritin, the transferrin receptor, enzymes of heme biosynthesis, DMT1, ferroportin and other protein.

Although most ferritin is located within the cells, a measurable amount of the protein exists in serum. Intracellular concentrations, particularly in the liver, are several orders of magnitude higher than serum concentration. Circulating ferritin consists almost exclusively of L-chain subunits. Intracellular ferritin contains a mixture of $\mathrm{H}$ and $\mathrm{L}$ subunits.

Ferritin can also be detected extracellularly, in cerebrospinal fluid and synovial fluid. In serum it is an extracellular ferritin that has been used extensively in diagnostic tests. In the clinical setting, serum ferritin evaluation is most commonly used to estimate body iron stores as low serum ferritin correlates with iron depletion, whereas high serum ferritin correlates with elevated body iron stores or with inflammation in patients with normal body iron stores., ${ }^{2,3}$

Serum ferritin levels decline with iron deficiency and rise with iron loading. In the absence of liver disease, infection, or chronic inflammation, serum ferritin is roughly proportional to total body iron stores. The correlation between serum ferritin levels and body iron stores is useful in the evaluation of patients with possible iron deficiency or iron overload. A low serum ferritin level less than $12 \mu \mathrm{g} / \mathrm{L}$ invariably represents iron deficiency and high serum ferritin levels are found in patients with iron overload. Extreme serum ferritin level should be interpreted with cautiously, however, because the correlation between ferritin levels and body iron stores is approximately linear only for storage reserves ranging from 1 to $3 \mathrm{~g}$. Normal circulating ferritin values vary with sex and age. These considerations must be factored into any evaluation of iron stores based on ferritin values, particularly in children.

Ferritin being acute phase reactant raises in several condition. Inflammation increases the serum ferritin concentration several fold. ${ }^{143}$ Infections, particularly chronic conditions such as tuberculosis or osteomyleitis may also increase levels substantially. Chronic renal disease and chronic liver disease are likewise associated with elevated levels. Ferritin is an important prognostic factor of childhood neuroblastoma, in which high levels of serum ferritin correlate with disease severity.

\section{Causes For Iron Deficiency ${ }^{144}$ \\ I. Deficient intake}

II. Increased demand

$$
\text { Dietary (milk, } 0.5-1.5 \mathrm{mg} \text { iron/L) }
$$

Growth (low birth weight, prematurity, low-birth-weight twins or multiple births, adolescence, pregnancy), cyanotic congenital heart disease. 


\section{Blood loss}

A. Perinatal

1. Placental

a. Transplacental bleeding into maternal circulation

b. Retroplacental (e.g., premature placental separation)

c. Intraplacental

d. Fetal blood loss at or before birth (e.g., placenta previa)

e. Fetofetal bleeding in monochorionic twins

f. Placental abnormalities

2. Umbilicus

a. Ruptured umbilical cord (e.g., vasa previa) and other umbilical cord

Abnormalities

b. Inadequate cord tying

c. Post-exchange transfusion

B. Postnatal

1. Gastrointestinal tract

a. Primary iron-deficiency anemia resulting in gut alteration with blood loss

Aggravating existing iron deficiency: 50\% of iron-deficient children have

Guaiac-postive stools

b. Hypersensitivity to whole cow's milk? due to heat-labile protein, resulting in blood loss and exudative enteropathy (leaky gut syndrome).

c. Anatomic gut lesions (e.g., varices, hiatus hernia, ulcer, leiomyomata, ileitis,Meckel's diverticulum, duplication of gut, hereditary

telangiectasia, polyps, colitis, hemorrhoids); exudative enteropathy

caused by underlying bowel disease (e.g., allergic gastroenteropathy,

intestinal lymphangiectasia)

d. Gastritis from aspirin, adrenocortical steroids, indomethacin,

phenylbutazone

e. Intestinal parasites (e.g., hookworm [Necator americanus])

f. Henoch-Schönlein purpura

2. Hepatobiliary system: hematobilia

3. Lung: Pulmonary hemosiderosis, Good pasture syndrome, defective iron mobilization with IgA deficiency

4. Nose: recurrent epistaxis

5. Uterus: menstrual loss

6. Heart: intracardiac myxomata, valvular prostheses or patches

7. Kidney: microangiopathic hemolytic anemia, hematuria, nephrotic syndrome (urinaryloss of transferrin), hemosiderinurias - chronic intravascular hemolysis (e.g., paroxysmal nocturnal hemoglobinuria, paroxysmal cold hemoglobinuria, march hemoglobinuria)

8. Extracorporeal: hemodialysis, trauma

\section{Impaired absorption}

Malabsorption syndrome, celiac disease, severe prolonged diarrhea, postgastrectomy, inflammatory bowel disease, Helicobacter pylori infection associated chronic gastritis.

Infants At High Risk For Iron Deficiency ${ }^{144}$

Increased iron needs:

Low birth weight

Prematurity

Multiple gestation

High growth rate

Chronic hypoxia - high altitude, cyanotic heart disease

Low hemoglobin at birth

Blood loss:

Perinatal bleeding

Dietary factors:

Early cow's milk intake

Early solid food intake

Rate of weight gain greater than average

Low-iron formula 
Frequent tea intake

Low vitamin $\mathrm{C}$ intake

Low meat intake

Breast-feeding $>6$ months without iron supplements

Low socioeconomic status (frequent infections)

\section{Tissue Effects Of Iron Deficiency}

\section{Gastrointestinal tract}

A. Anorexia - common and an early symptom

1. Increased incidence of low-weight percentiles

2. Depression of growth

B. Pica-pagophagia (ice) geophagia (sand)

C. Atrophic glossitis

D. Dysphagia

E. Esophageal webs (Kelly-Paterson syndrome)

F. Reduced gastric acidity

G. Leaky gut syndrome

1. Guaiac-positive stools - isolated

2. Exudative enteropathy: gastrointestinal loss of protein, albumin, immunoglobulins, copper, calcium, red cells

H. Malabsorption syndrome

1. Iron only

2. Generalized malabsorption: xylose, fat, vitamin A, duodenojejunal mucosal

I. Beeturia Atrophy

J. Decreased cytochrome oxidase activity and succinic dehydrogenase

K. Decreased disaccharidases, especially lactase, with abnormal lactose tolerance tests

L. Increased absorption of cadmium and lead (iron-deficient children have increased

lead absorption)

M. Increased intestinal permeability index

\section{Central nervous system}

A. Irritability

B. Fatigue and decreased activity

C. Conduct disorders

D. Lower mental and motor developmental test scores on the Bayley scale that may be long lasting

E. Decreased attentiveness, shorter attention span

F. Significantly lower scholastic performance

G. Reduced cognitive performance

H. Breath-holding spells

I. Papilledema

\section{Cardiovascular system}

A. Increase in exercise and recovery heart rate and cardiac output

B. Cardiac hypertrophy

C. Increase in plasma volume

D. Increased minute ventilation values

E. Increased tolerance to digitalis

\section{Musculoskeletal system}

A. Deficiency of myoglobin and cytochrome C

B. Impaired performance of a brief intense exercise task

C. Decreased physical performance in prolonged endurance work

D. Rapid development of tissue lactic acidosis on exercise and a decrease in mitochondrial $\alpha$-glycerophosphate oxidase activity

E. Radiographic changes in bone - widening of diploic spaces

F. Adverse effect on fracture healing 


\section{Immunologic system}

There is conflicting information as to the effect on the immunologic system of irondeficiency anemia.

A. Evidence of increased propensity for infection

1. Clinical

a. Reduction of acute illness and improved rate of recovery in iron-replete

Compared to iron-deficient children

b. Increased frequency of respiratory infection in iron deficiency

2. Laboratory

a. Impaired leukocyte transformation

b. Impaired granulocyte killing and nitroblue tetrazolium (NBT) reduction by granulocytes

c. Decreased myeloperoxidase in leukocytes and small intestine

d. Decreased cutaneous hypersensitivity

e. Increased susceptibility to infection in iron-deficient animals

B. Evidence of decreased propensity for infection

1. Clinical

a. Lower frequency of bacterial infection

b. Increased frequency of infection in iron overload conditions

2. Laboratory

a. Transferrin inhibition of bacterial growth by binding iron so that no free iron Is available for growth of microorganisms

b. Enhancement of growth of nonpathogenic bacteria by iron

\section{Cellular changes}

A. Red cells

1. Ineffective erythropoiesis

2. Decreased red cell survival (normal when injected into asplenic subjects)

3. Increased autohemolysis

4. Increased red cell rigidity

5. Increased susceptibility to sulfhydryl inhibitors

6. Decreased heme production

7. Decreased globin and $\alpha$-chain synthesis

8. Precipitation of $\alpha$-globin monomers to cell membrane

9. Decreased glutathione peroxidase and catalase activity

a. Inefficient hydrogen peroxide $(\mathrm{H} 2 \mathrm{O} 2)$ detoxification

b. Greater susceptibility to $\mathrm{H} 2 \mathrm{O} 2$ hemolysis

c. Oxidative damage to cell membrane

d. Increased cellular rigidity

10. Increased rate of glycolysis-glucose 6-phosphate dehydrogenase,6-phosphogluconate dehydrogenase, 2,3diphosphoglycerate (2,3-DPG), and glutathione

11. Increase in NADH-methemoglobin reductase

12. Increase in erythrocyte glutamic oxaloacetic transaminase (EGOT)

13. Increase in free erythrocyte protoporphyrin

14. Impairment of DNA and RNA synthesis in bone marrow cells

B. Other tissues

1. Reduction in heme-containing enzymes (cytochrome $\mathrm{C}$, cytochrome oxidase)

2. Reduction in iron-dependent enzymes (succinic dehydrogenase, aconitase)

3. Reduction in monoamine oxidase (MAO)

4. Increased excretion of urinary norepinephrine

5. Reduction in tyrosine hydroxylase (enzyme converting tyrosine to dihydroxyphenylalanine)

6. Alterations in cellular growth, DNA, RNA, and protein synthesis in animals

7. Persistent deficiency of brain iron following short-term deprivation

8. Reduction in plasma zinc 


\section{Iron And Brain}

Behavioral and cognitive dysfunctions are most worrisome manifestations of Iron deficiency. Recent research has revealed that anemia is a late manifestation of iron deficiency, brain iron deficiency occurs even with normal levels of hemoglobin, as iron is prioritized to red blood cells over all other organs including brain. ${ }^{6}$ The biological basis of the behavioral and cognitive developmental delays observed in iron-deficient infants is not completely understood but possibilities include:

a. abnormalities in neurotransmitter metabolism

b. decreased myelin formation, and

c. alterations in brain energy metabolism. ${ }^{5}$

Brain growth spurt takes place in last trimester of fetal life and continues during first two years of childhood. Animal studies have revealed that brain iron content is maximum at birth, decreases during early infancy and again increases with weaning. Brain iron has heterogenous distribution in brain with basal ganglia, substantia nigra and deep cerebellar nuclei being richer in iron content. ${ }^{5}$ Iron deficiency during this period of growth spurt has been shown to be associated with irreversible cognitive and developmental delay. Besides this, developing human hippocampus, an area involved in memory processing, is much more vulnerable to perinatal iron deficiency. ${ }^{6}$

Evoked potential studies have been undertaken to look for adverse effects of iron deficiency on neural tissues. These studies have advantage of avoiding potential inherent confounding factors including anemia and low socioeconomic status. Many of these studies have reported longer latencies on brainstem auditory evoked potential and visually evoked potentials in formerly iron deficient children, suggestive of hypo myelination in these children.

Iron is used as cofactor for metabolism of many neurotransmitters, monoamine and aldehyde oxidase in the brain. ${ }^{27}$ The metabolism of these neurotransmitter, monoamine and aldehyde oxidase will be affected in the patient with iron deficiency leading to decrease in these neurotransmitter, which may decrease the threshold for seizure. ${ }^{26}$ Fever can worsen the negative effects of low serum ferritin on the brain and trigger seizure. ${ }^{27}$ Brain iron distribution is related to the distribution of gamma aminobutyric acid (GABA) systems. The high iron regions of the brain receive GABAergic input. Iron deficiency decreases GABA related enzymes and increases GABA receptors.

\section{Diagnosis \\ Diagnostic Evaluation}

As soon as the child is brought to medical attention following an apparent febrile convulsion, it is important to identify whether any medical condition is present that requires treatment. The history should include possible symptoms of infectious illness, trauma, medication taken, exposures to toxins, developmental level, and any previous or family history of seizures, either febrile or afebrile. Whenever possible, a complete description of the seizure from start to finish should be obtained from an eyewitness. This history may be unreliable because caretakers are often very frightened by the seizure.

A general physical examination should note the level of consciousness and presence or absence of meningismus, tense or bulging fontanelle, Kernig or Brudzinski signs, and focal differences or abnormality in muscle strength and tone. Urgent attention must be given to exclude the presence of meningitis and status epilepticus.

For children with many febrile seizures, it is important to consider a chronic infection or immune deficiency. Two practice parameters prepared for the American Academy of Pediatrics, based on peer-reviewed publications about simple febrile seizures, ${ }^{145,146}$ have concluded that very little investigation is warranted.

\section{Routine Blood Work}

Routine blood work has not been shown to be of value. Two studies have suggested that low serum sodium after a first febrile seizure is associated with a significant risk of a recurrent febrile seizure within that illness; ${ }^{147,148}$ however, another more robust study failed to confirm this association.149 Because rates of bacteremia (2\%) and other serious bacterial illnesses are low (2\%), blood cultures and complete blood count are not routinely necessary.

\section{Lumbar Puncture}

The main controversy in the evaluation of febrile seizures continues to be the Lumbar puncture (LP). About $15 \%$ of children with meningitis will have seizures, but virtually none are neurologically normal shortly after the seizure. ${ }^{150}$ Once a febrile seizure has stopped, excluding meningitis/encephalitis becomes a critical task for the physician. A LP is indicated if meningitis is suspected clinically, even if a source of infection outside the CNS has been found, such as otitis media. If the infant has been receiving antibiotics, partially treated 
meningitis should be considered. In infants younger than 12 to 18 months, clinical signs of meningitis may be absent, and a LP should be strongly considered. ${ }^{151}$ However, this clinical truism has not been critically assessed.

The American Academy of Pediatrics Committee on Quality Improvement Committee practice parameter states: "The clinical evaluation of young febrile children requires skills that vary among examiners. In all children younger than 12 months, performance of a lumbar puncture should be strongly considered." ${ }^{146}$ In the slightly older child, the practice parameter maintains: "In a child between 12 to 18 months of age, a LP should be considered because clinical signs and symptoms of meningitis may be subtle". 152

The LP should not be omitted solely on the basis of age or family history, and it should be considered even in a child who has had several previous febrile seizures. If increased intracranial pressure is suspected, the decision to perform a LP should be made by an experienced physician who is able to weigh the risk of delaying a possible diagnosis of meningitis against the risk of LP. It is clear that meningitis is incredibly unlikely if a child older than 18 months of age appears well shortly after the seizure. The American Academy of Pediatrics Committee on Quality Improvement Committee stated, "In a child older than 18 months, although a lumbar puncture is not routinely warranted, it is recommended in the presence of meningeal signs and symptoms. In addition, if the child has previously been treated with antibiotics, the clinician should be aware that the signs and symptoms of CNS infection may become masked, and lumbar puncture should be strongly considered in such cases". 146

In one series, of 503 children with meningitis, none had a simple febrile seizure. ${ }^{150}$ Offringa studied 309 children who had an LP after presenting to an emergency department with a seizure associated with fever. ${ }^{153}$ Ten cases had meningitis (bacterial or viral), and all had major signs pointing to serious illness. Six other children had the same signs but did not have meningitis. Therefore, only 16 of 309 "needed" an LP to exclude a CNS infection.

An older study by Lorber suggested that an experienced pediatrician could avoid many LPs without missing cases of meningitis. ${ }^{154}$ Such a selective approach implies that the physician assessing the child is experienced with the kinds of symptoms that are associated with meningitis in children. This judgment seems to be based on "the child appeared more ill than the physical signs suggested; had photophobia, neck stiffness, or a positive Kernig sign; had continuing pyrexia without obvious cause; or deteriorated in hospital". 153 The contention that "lack of experience by junior doctors does not justify routine lumbar puncture" must be tempered by what is realistically possible. ${ }^{154}$ We suggest following the practice parameter recommendation (noted earlier) to perform a LP if the child is less than 12 months of age, unless an experienced pediatrician is available to assist.

\section{Neuroimaging}

The published evidence indicates no proven benefit for neuroimaging in children with either simple or complex febrile seizures. Neuroimaging would appear justified only when special evidence points to an underlying structural lesion such as focal neurologic abnormalities, significant developmental delay, neurocutaneous lesions or abnormal head circumference. ${ }^{146}$ Anxiety about complex febrile seizures does not justify routine imaging, especially considering that this group involves $30 \%$ to $40 \%$ of all first febrile seizures. No abnormalities were found in one study of computed tomography (CT) scans in 44 hospitalized febrile seizure patients. ${ }^{155}$

\section{Electroencephalograph}

Routine electroencephalography (EEG) is not justified after a first simple febrile seizure, either at the time of presentation or within the following month. ${ }^{146}$ Even though EEG is often requested, no consistent evidence suggests that routine EEG predicts febrile seizure recurrence or subsequent epilepsy. ${ }^{156}$, 157 Furthermore, studies of children with complex febrile seizures have not shown the EEG to be predictive of the development of epilepsy.

The one special feature of the EEG and febrile seizures is hypnagogic spike wave. This discharge consists of short bursts of irregular high-voltage $\delta$-waves with a few buried spikes as the child drifts off to sleep. It has a peak expression at about to 4 years of age - long after the peak age of febrile seizures - and apparently may be seen in the majority of children with febrile seizures. ${ }^{158}$ Many authorities view hypnagogic spike-wave as an expression or marker of the febrile seizure tendency but, in any case, it carries no long-term negative connotations. The value of EEG in children with repeated febrile seizures has apparently not been extensively studied.

\section{Differential Diagnosis}

Rigors due to fever, febrile myoclonus, breath-holding, and syncope triggered by illness must be differentiated from febrile seizures. ${ }^{159}$ It is possible that many febrile seizures are febrile syncope, a diagnosis 
that should be suspected on the semiology of reflex asystolic attacks accompanied by sudden pallor and atonic collapse or tonic extension.

A new scenario of an afebrile seizure associated with minor infection was described by Lee. ${ }^{159}$ The age group is similar to those with febrile seizures, and a high prevalence of family history of febrile seizures is noted. Children with this disorder frequently have febrile seizures on other occasions. The seizures occur in children who are afebrile (temperature $<37.8^{\circ} \mathrm{C}$ ), have definite signs or symptoms of illnesses (cough, coryza, vomiting, or diarrhea), and have normal metabolic and cerebrospinal fluid findings and no other obvious cause for seizures. Nearly $25 \%$ of the 125 children had more than one recurrent seizure within the next 24 hours. After a follow-up of 6 years, the risk of recurrence of an afebrile seizure was $7.8 \%$, as compared with $1.6 \%$ followed having a first unprovoked (regular) febrile seizure. There is an overlap in presentation between febrile and illness-provoked seizures. We are not convinced that including them within the acute symptomatic group is appropriate, as mentioned previously. The appropriate initial evaluation for cause of seizures is similar, as is the supportive care, counseling, and long-term management.

\section{Blood}

1. Hemoglobin: Hemoglobin is below the acceptable level for age. ${ }^{82,83}$ Infants 0.5 to 4.9 years $<11$ $\mathrm{g} / \mathrm{dL}(110 \mathrm{~g} / \mathrm{L})$ Children 5.0 to 11.9 years $<11.5 \mathrm{~g} / \mathrm{dL}(115 \mathrm{~g} / \mathrm{L})$

\begin{tabular}{|l|l|}
\hline Infants 0.5 to 4.9 years & $<11 \mathrm{~g} / \mathrm{dL}(110 \mathrm{~g} / \mathrm{L})$ \\
\hline Children 5.0 to 11.9 years & $<11.5 \mathrm{~g} / \mathrm{dL}(115 \mathrm{~g} / \mathrm{L})$ \\
\hline
\end{tabular}

2. Red cell indices: Lower than normal $\mathrm{MCV}, \mathrm{MCH}$, and $\mathrm{MCHC}$ for age. Widened red cell distribution width (RDW) in association with a low MCV is one of the best screening tests for iron deficiency. In iron deficiency it is more than 15 (normal value $11-15 \%$ ).

3. Blood smear: Red cells are hypochromic and microcytic with anisocytosis and poikilocytosis, generally occurring only when the hemoglobin level falls below $10 \mathrm{~g} / \mathrm{dL}$. Basophilic stippling can also be present but not as frequently as it is present in thalassemia trait. The RDW is high $(>15 \%)$ in iron deficiency and normal is $11^{11,12,13,14,15}$

4. Reticulocyte count: The reticulocyte count is usually normal; however, in severe iron-deficiency anemia associated with bleeding, a reticulocyte count of 3-4\% may occur.

5. Platelet count: The platelet count varies from thrombocytopenia to thrombocytosis. Thrombocytopenia is more common in severe iron-deficiency anemia; thrombocytosis is present when there is associated bleeding from the gut.

6. Free erythrocyte protoporphyrin: The incorporation of iron into protoporphyrin

represents the ultimate stage in the biosynthetic pathway of heme. Failure of iron supply will result in an accumulation of free protoporphyrin not incorporated into heme synthesis in the normoblast and the release of erythrocytes into the circulation with high free erythrocyte protoporphyrin (FEP) levels. In both iron deficiency and lead poisoning, the FEP level is elevated. It is much higher in lead poisoning than in iron deficiency. The FEP is normal in $\alpha$ - and $\beta$-thalassemia minor. FEP elevation occurs as soon as the body stores of iron are depleted, before microcytic anemia develops. An elevated FEP level, therefore, is an indication for iron therapy even when anemia and microcytosis have not yet developed.

7. Serum ferritin: The level of serum ferritin reflects the level of body iron stores; it is quantitative, reproducible, specific, and sensitive and requires only a small blood sample. A concentration of less than 12 $\mathrm{ng} / \mathrm{mL}$ is considered diagnostic of iron deficiency. Normal ferritin levels, however, can exist in iron deficiency when bacterial or parasitic infection, malignancy, or chronic inflammatory conditions coexist because ferritin is an acute-phase reactant.

8. Serum iron and iron saturation percentage: Serum iron estimation as a measure of iron deficiency has serious limitations. It reflects the balance between several factors, including iron absorbed, iron used for hemoglobin synthesis, iron released by red cell destruction, and the size of iron stores. The serum iron concentration represents equilibrium between the iron entering and leaving the circulation. Serum iron has a wide range of normal, varies significantly with age, and is subject to marked circadian changes (as much as 100 $\mu \mathrm{g} / \mathrm{dL}$ during the day. Serum iron not used for the routine diagnosis of iron deficiency (in favor of MCV, RDW, FEP, and serum ferritin) because of the following limitations:

A. Wide normal variations (age, sex, laboratory methodology)

B. Time consuming

C. Subject to error from iron ingestion

D. Diurnal variation

E. Falls in mild or transient infection.

9. Therapeutic trial: The most reliable criterion of iron-deficiency anemia is the hemoglobin response to an adequate therapeutic trial of oral iron. A reticulocytosis with a peak occurring between the 5th and 10th days followed by a significant rise in hemoglobin level occurs. The absence of these changes implies that 
iron deficiency is not the cause of the anemia. Iron therapy should then be discontinued and further diagnostic studies implemented.

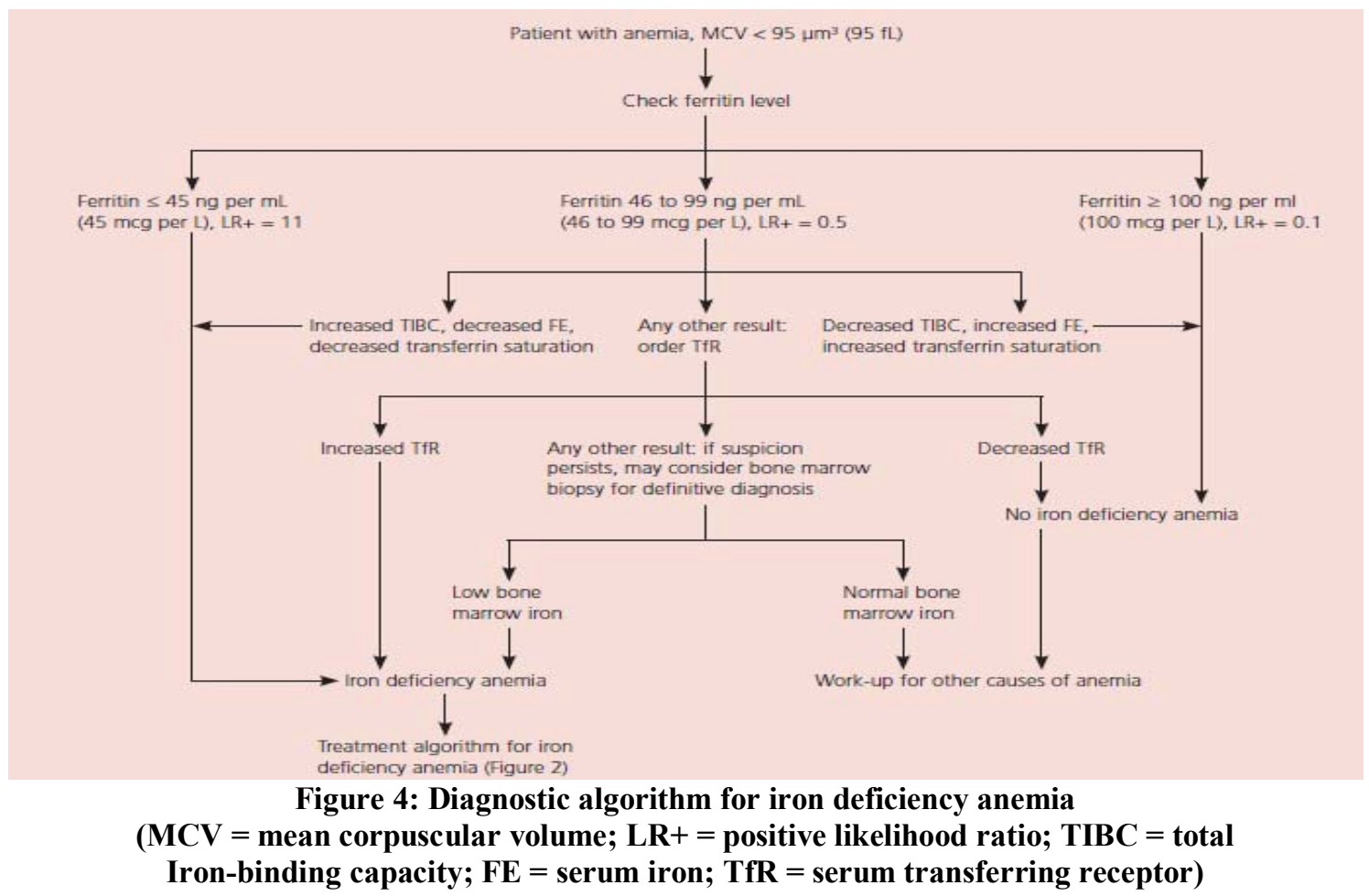

In progressive iron deficiency, a sequence of biochemical and hematological events occurs. First, the tissue iron store represented by bone marrow hemosiderin disappears. The level of serum ferritin, an iron storage protein provides a relatively accurate estimate of body iron stores in the absence of inflammatory disease. Normal ages are age dependent and decreased level accompanies iron deficiency. Next, serum iron decreases (also age dependent), the iron binding capacity of serum (serum transferrin) increases, and the percentage saturation (transferrin saturation) falls below normal. When the availability of iron becomes rate limiting step in hemoglobin synthesis, free erythrocyte protoporphyrin (FEP) accumulates. ${ }^{60}$

As the deficiency progresses, the red blood cells (RBC) becomes smaller than normal, and the hemoglobin content decreases. Then the morphologic characteristics of RBC's are best determined by determination of mean corpuscular volume, (MCV), mean corpuscular hemoglobin $(\mathrm{MCH})$. With increasing deficiency, the RBC's become deformed and misshapen and present characteristics microcytosis, hypochromia, poilokiocytosis, increased RBC distribution width (RDW). ${ }^{160,161}$

Although they do not always show a linear relationship to iron stores, ferritin levels are the single best serum measure of storage iron. Normal blood levels of serum ferritin are 30-300 ng/mL for males and 15-200 $\mathrm{ng} / \mathrm{mL}$ for female. ${ }^{160,162}$

In iron deficiency anemia, the value is less than $12 \mu \mathrm{g} / \mathrm{L}$ in the absence of a complicating disease. When an infectious or inflammatory disease like rheumatoid arthritis is also present, the serum ferritin level is usually higher, but it is generally less than 50 to $60 \mu \mathrm{g} / \mathrm{L}$. Of all the serum tests for iron deficiency, the serum ferritin determination is the most useful, and a low serum ferritin invariably signifies iron deficiency. ${ }^{161,162,163,164}$ Bone marrow biopsy provides the most accurate of body iron stores but the procedure is a painful and difficult to do in all patients. Under steady state conditions, the serum ferritin level correlates with total body iron stores; thus, the serum ferritin is the most convenient laboratory test to estimate iron stores. ${ }^{85,165,166,167,168}$

As ferritin is also an acute-phase reactant, it is often elevated in the course of disease. A normal Creactive protein can be used to exclude elevated ferritin caused by acute phase reactions.

\section{Zinc and Brain:}

Zinc is an essential trace element, necessary for plants, animals, and microorganisms. Zinc is found in nearly 100 specific enzymes (other sources say 300), serves as structural ions in transcription actors and is stored and transferred in metallothioneins. It is "typically the second most abundant transition metal in organisms" after iron and it is the only metal which appears in all enzyme classes. 
In proteins, $\mathrm{Zn}$ ions are often coordinated to the amino acid side chains of aspartic acid, glutamic acid, cysteine and histidine. The theoretical and computational description of this zinc binding in proteins (as well as that of other transition metals) is difficult.

There are 2-4 grams of zinc distributed throughout the human body. Most zinc is in the brain, muscle, bones, kidney, and liver, with the highest concentrations in the prostate and parts of the eye. Semen is particularly rich in zinc, which is a key factor in prostate gland function and reproductive organ growth.

In humans, zinc plays "ubiquitous biological roles". It interacts with "a wide range of organic ligands", and has roles in the metabolism of RNA and DNA, signal transduction, and gene expression. It also regulates apoptosis. A 2006 study estimated that about $10 \%$ of human proteins (2800) potentially bind zinc, in addition to hundreds which transport and traffic zinc; a similar in silico study in the plant Arabidopsis thaliana found 2367 zinc-related proteins.

In the brain, zinc is stored in specific synaptic vesicles by Glutamatergic neurons and can "modulate brain excitability". It plays a key role in synaptic plasticity and so in learning. However it has been called "the brain's dark horse" since it also can be a neurotoxin, suggesting zinc homeostasis plays a critical role in normal functioning of the brain and central nervous system.

Several theories, such as genetic basis, reduction of serum as well as cerebrospinal fluid (CSF) zinc and magnesium level and low Gamma- aminobutyric acid (GABA) have been proposed. Low CSF GABA values have been reported in association with several seizure disorders, including febrile convulsion.

Zinc is known to play a control role in the immune system, and zinc- deficient persons experience increased susceptibility to a variety of pathogens. Zinc also functions as an antioxidant and can stabilize membranes.

Zinc is a micronutrient that is essential for the normal functioning of the central nervous system. It is needed for synthesis of gamma-amino butyric acid, an inhibitory neurotransmitter, and complements the inhibitory effects of calcium on the excitatory N-methyl-D-aspartate. When a patient develops low levels of zinc, the N-methyl-D-aspartate receptors become activated and induce an epileptic discharge in children with high fevers.

\section{Treatment Of Febrile Seizures}

Treatment of febrile seizures is a controversial subject. Two major rationales for the treatment have evolved, each of which leads to different approaches. The first approach is based on the old idea that febrile seizures are harmful, and may lead to development of epilepsy and is aimed at preventing febrile seizures, using either intermittent or chronic treatment with medications. ${ }^{169,170}$

The second approach is based on the epidemiologic data that febrile seizure is by and large benign. Therefore, the only concern is about prolonged febrile seizure. This singular concern leads to a therapeutic approach that does not treat brief febrile seizures. ${ }^{171,172}$

Preventing or absorbing prolonged febrile seizures to prevent status epilepticus with its attendant complications, however, remains a rational goal. ${ }^{172}$

\section{Terminating A Febrile Seizure \\ In hospital management}

If seizure activity is ongoing when the child arrives at the emergency department, treatment to terminate the seizure is mandatory. Intravenous Lorazepam $0.1 \mathrm{mg} / \mathrm{kg} / \mathrm{dose} / \mathrm{iv}$ diazepam $0.3 \mathrm{mg} / \mathrm{kg} / \mathrm{dose}$ is effective in most cases. ${ }^{173,74}$

Rectal diazepam or diazepam gel also is appropriate for use in pre-hospital setting, such as ambulance and in cases in which intravenous access is difficult. If the seizure activity continues after an adequate dose of a benzodiazepine, than a full status epilepticus treatment protocol should be used. ${ }^{173,174}$

\section{Preventing A Febrile Seizures \\ Intermittent Medication at Time of Fever \\ Antipyretics}

Studies support that the risk of febrile seizure is directly related to the height of fever. Paracetamol at dose of $15 \mathrm{mg} / \mathrm{kg} /$ dose QID is effective as antipyretics. ${ }^{16,17}$

\section{Benzo Diazepines}

Diazepam given orally or rectally at the time of onset of a febrile illness will reduce the probability of a febrile seizure. Although the effect is statistically significant, it is clinically modest. This modest reduction in seizure recurrence must be weighed against the side effects of sedating children every time they have a febrile illness. 


\section{Barbiturates}

Intermittent therapy with Phenobarbital at the onset of fever is ineffective in reducing the risk of recurrent febrile seizures. Nevertheless, it is fairly widely used for this purpose. ${ }^{172}$

\section{Daily Medications}

Barbiturates

Phenobarbital, give daily at doses that achieve a blood level of $15 \mu \mathrm{g} / \mathrm{ml}$ or higher, was effective in reducing the risk of recurrent febrile seizures in several well controlled trials. ${ }^{175,176}$ However, substantial proportion of the children demonstrated adverse effects, primarily hypersensitivity, that required discontinuation of epilepsy. Prolonged Phenobarbital therapy is rarely indicated because the risks seem to outweigh the benefits in most cases. ${ }^{171,172}$

\section{Valproate}

Daily treatment with valproic acid also has been found to be effective in reducing the risk of recurrent febrile seizure. Fatal idiosyncratic hepatotoxicity limits the use in children. ${ }^{171,172}$

\section{Preventing Epilepsy}

Antiepileptic drugs are effective in lowering the risk of a recurrent seizure, whether febrile or afebrile, but are ineffective in preventing the development of subsequent epilepsy, whether in the setting of febrile seizures or acute post-traumatic seizures. ${ }^{173}$

\section{Treatment}

The most important steps in the evaluation and treatment of iron deficiency are determining the cause and correcting the abnormality. Growth spurts, poor dietary pattern are much more common for iron deficiency. Oral iron supplementation usually replaces stores most efficiently.

\section{Oral supplementation}

Iron salts offer inexpensive, effective therapy for iron deficiency. Iron is frequently provided to children at a dose of $3 \mathrm{mg} / \mathrm{kg} / \mathrm{day}$, into 3 times a day dosing. Single dose daily regimens, however, are tolerated as well as TID regimens ${ }^{86}$ administration of iron as an empty stomach at night will lessen the GI difficulties. The decreased GI motility of sleep will also enhance absorption.

The absorptive capacity of the normal duodenum for iron is essentially saturated with about $25 \mathrm{mg}$ of elemental iron in ferric form.

Ferric gluconate contains about $50 \mathrm{mg}$ of elemental iron tablet. This form of replacement may produce fewer problems than ferrous SO4 and is excellent as the initial treatment of iron deficiency. Ascorbic acid supplementation enhances iron absorption, although it has a relatively minor effect in individuals ingesting normal, balanced diets. ${ }^{86}$

Even with faithful use of oral iron, adequate replacement of iron stores in patients with moderate iron deficiency anemia requires several months with ongoing blood loss, replacement of stores with oral iron becomes very difficult. Polysaccharide/iron complexes differ from iron salts.

Polar oxygen groups in the sugar form coordination complexes with iron atoms. The well-hydrated microspheres of polysaccharides iron remain in solution over a wide range of $\mathrm{pH}$ values. Most patients tolerate this form of iron better than iron salts.

\section{Reasons for poor response to oral iron:}

- Non-compliance

- On-going blood loss

- Insufficient duration of therapy

- High gastric $\mathrm{pH}$

- Antacids

- Histamine $\mathrm{H} 2$ blockers

- Gastric proton pump inhibitors

- Inhibitors of iron absorption/utilisation

○ Lead

- Aluminium intoxication (hemo dialysis patient)

- Chronic infection

- Neoplasia

- Incorrect diagnosis

o Thalassemia trait

o Sideroblastic anemia, anemia of chronic inflammation 


\section{Parental Iron Replacement}

- Iron dextran

- Iron gluconate

- Iron sucrose

\section{Indication}

- Oral iron is poorly tolerated

- Rapid replacement of iron store is needed

- GI iron absorption is compromised

- $\quad$ EPO treatment is necessary, particularly in renal dialysis patient

Intramuscular - Iron dextran is - painful and if leaked into subcutaneous tissue - leads to long standing skin discoloration. A " $Z$ track" injection into the muscle decreases the chances of subcutaneous leakage. The sub optimal muscle mass frequently with nutritional deficiency further complicates this mode of replacement.

IV infusion circumvents these problems altogether. A test dose should be given before either IV or IM. Rarely fatal anaphylactic reactions can occur. The newer iron, sucrose, iron gluconate preparations are believed to be less likely to cause complication.

of Iron dextran

$10-15 \%$ of patient experience transient mild to moderate arthralgia, the day after IM/IV administration

Dose $(\mathrm{ml})=.0442 \times($ Described tab - observed $\mathrm{Hb}) \times$ lean body weight $+(0.25 \times$ lean Body weight $)$

\section{Review Of Literature}

Pisacane A et al ${ }^{4}$ conducted a case control study in 1996, in 156 children less than 2 years, to know the relationship of iron deficiency and febrile seizure. Two groups were selected. A random group of children admitted to same ward with respiratory or gastrointestinal infection during that period and a group of healthy children randomly selected from the provincial birth register for an iron deficiency survey. He reported that fever can worsen the negative effects of anemia or of iron deficiency on brain and a seizure can occur as a consequence.

Azhar's Daoud et al ${ }^{6}$ conducted a controlled study to investigate the relation of iron store and first febrile seizures by prospectively measuring hemoglobin $(\mathrm{Hb} \%)$, mean corpuscular volume (MCV), mean corpuscular hemoglobin $(\mathrm{MCH})$, and plasma ferritin (PF) in 75 children with first febrile seizure and comparing them with 75 controls matched for age and sex with febrile illness without convulsion in 2002. They found mean plasma ferritin level was significantly lower in children with first febrile seizure $\left(29.5+\_21.3 \mathrm{microg} / \mathrm{L}\right)$ than in controls $(53.3+-37.6 \mathrm{microg} / \mathrm{L})$ with $\mathrm{p}$ value 0.0001 . The study gave conclusion that plasma ferritin level was significantly lower in children with first febrile seizure than in reference group, suggesting a possible role for iron insufficiency in first febrile seizure.

Parade Auvichayapat et al ${ }^{9}$ conducted a descriptive study in 430 thalassemic patients aged between 6 months and 10 years at 2 hospitals in north eastern Thailand. 20 patients had siblings who had febrile seizure. The incidence was 1.1 per 1000 person years as compared to $2-5 \%$ or 4.8 per 1000 person year. This was statistically significant with $\mathrm{p}$ value of 0.002 . Therefore, the rate in thalassemia patients was 4.4 times lower than that of general population. Thus, iron overload may have a major factor affects brain metabolism and thereby prevents febrile seizures.

Naveed Ur Rehman; Billoo ${ }^{8}$ A G conducted a case control study in 2005 at paediatrics department of the Aga Khan university hospital Karachi to find the association between iron deficiency anemia and febrile convulsions among 60 children dividing them into 2 groups with children having febrile seizure comprised as cases and while those with febrile illness without seizure comprised as controls. Both the groups had equal number of children and were matched for age and gender. In there study they found iron deficiency anemia was significantly more frequent among the cases as compared to controls with $\mathrm{p}$ value for $\mathrm{Hb} \%<10 \mathrm{~g} / \mathrm{dl}(\mathrm{p}=<0.000)$, hematocrit $<30 \% \quad(\mathrm{p}=<0.01), \mathrm{MCV}<70 \mathrm{fl}(\mathrm{p}=<0.002), \mathrm{MCH}<24 \mathrm{pg} \quad(\mathrm{p}-<0.001)$ and serum ferritin $<10 \mathrm{ng} / \mathrm{ml}$ $(\mathrm{p}=<0.0000)$. They gave conclusion in their study that plasma ferritin was significantly lower in cases as compared to controls suggesting that iron deficient children are more prone to febrile seizure and suggested for a follow up study of patient found to be iron deficiency at the time of a first febrile seizure to determine the incidence of subsequent febrile seizure after treatment for iron deficiency.

Dawn S Hartfield Jonathan Tan et al ${ }^{7}$ conducted case controlled study in 2009 to determine the association between iron deficiency and febrile seizure in childhood. They conducted a retrospective case control study with 361 patients aged 6 to 36 months who present with febrile seizure and 390 otherwise healthy controls who presented with a febrile illness to emergency department were reviewed to determine the iron status using MCV, RDW and hemoglobin. The results showed that a total of $9 \%$ of case had iron deficiency and $6 \%$ of had iron deficiency anemia compared to $5 \%$ and $4 \%$ of controls respectively. The gave conclusion that 
Children with febrile seizure were almost twice as likely to be iron deficient as those with febrile illness alone and they suggested to screen for iron deficiency with children presents with febrile seizure.

Rajwanti K Vaswani, Praveen G D et al ${ }^{5}$ conducted study among 100 children in 2009, dividing equally children between 6 months and 6 years with first febrile seizure as cases and febrile illness with out seizure as controls. Iron deficiency was determined by estimation of hemoglobin, red blood cell indices and serum ferritin. Iron deficiency anemia was defined as hemoglobin $11 \mathrm{gm} / \mathrm{dl}, \mathrm{MCV}<70 \mathrm{fl}, \mathrm{MCH}<27 \mathrm{pg}$ and serum ferritin $<12$ microgram/dL. In presence of fever a higher cutoff value of serum ferritin $(25-50 \mathrm{microgram} / \mathrm{dL})$ was considered. Cases and controls were compared with respect to blood indices and serum ferritin level. The results of this study showed the proportion of children with low ferritin $(<25$ microgram/L) was significantly higher in cases $(34.68 \%)$ than in controls $(15.30 \%)$ with value of $<0.0001$. the concluded that iron deficiency could be a potential risk factor for febrile seizure in children.

Dr.R Ganesh Et al ${ }^{178}$ from Kanchi Kamacoti Childs trust hospital, India, evaluated zinc levels in 38 previously healthy children between 3 months and 5 in age, who were admitted in the hospital with fever-related seizures. The investigators also evaluated 38 similar children, without febrile seizures. The average zinc levels were significantly lower in children with febrile seizures compared with the controls. Although their study population was small and has the limitation of being hospital, they concluded that the use of zinc supplements in reducing the rate of febrile seizures in children should be investigated.

Burhanoglum, Ehsani et $\mathrm{a}^{180}$ have reported that the serum zinc level in children with febrile seizure is lower than in control group and concluded that this trace element may have a role in febrile seizure.

Mahyar et a ${ }^{181}$ did a case control study at IRAN comparing 52 children between 9 months and five years with first episode of febrile seizure with 52 healthy children in the same age group. The mean serum zinc levels in the patient group were $62.8 \mathrm{mcg} / \mathrm{dl}$ and in the control group was $85.7 \mathrm{mcg} / \mathrm{dl}$. The difference was statistically significant indicating that hypozinconemia predisposes to febrile seizures.

Fahimeh Ehsanipour, Mahshid Talibi Taher, Nahid Vahid Harandi ${ }^{182}$ from the Dept of Pediatrics, Iran university of Medical Sciences, Tehran IR Iran. Prospective analytical case control study was conducted in Rasoul-e-Akram teaching hospital from Jan 2003-Jan2005.The study included 92 children between 6 months to 5 years of both sexes. 34 with febrile seizures (Group A), 18 with non febrile convulsions(Group B) and 40 with fever without convulsions(Group C).Serum Zn levels of all group A, B, C was estimated by atomic absorption spectrophotometry

Serum Zn levels in

- Group A - 76.82 $\pm 24.36 \mathrm{mg} / \mathrm{L}$

- Group B $-90.12 \pm 14.63 \mathrm{mg} / \mathrm{L}$

- Group C $-94.53 \pm 17.39 \mathrm{mg} / \mathrm{L}$

Serum $\mathrm{Zn}$ level of A was lower than other 2 group $(\mathrm{p}<0.006)$

Modarresi MR et $\mathrm{al}^{183}$ did a cross sectional study, 90 patients aged 9 months to 5 years Were studied in a period of 12 months. They were assigned to three groups. Thirty patients were included in the Febrile Seizure group, thirty febrile children without convulsion or previous history of convulsion were included in the febrile group and thirty afebrile healthy ones were enrolled as controls. Venous blood was obtained and $\mathrm{Zn}$ concentration in serum was measured using Graphite Furnance Atomic Absorbance Spectrophotometering. There findings showed that Zinc level was significantly lower in the febrile seizure group compared to two other groups.

Mojtabaamiriet $\mathrm{al}^{184}$ studied serum selenium, zinc and copper levels in children with febrile convulsion and healthy children. The mean serum zinc levels were $66.9 \mathrm{mcg} / \mathrm{dl}$ and $107 \mathrm{mcg} / \mathrm{dl}$ among cases and controls respectively. the serum selenium were $44.9 \mathrm{mcg} / \mathrm{dl}$ and $62.8 \mathrm{mcg} / \mathrm{dl}$ among cases and controls respectively. There were no differences in copper levels of the two groups. This study showed that both decreased serum zinc and selenium levels play a role in febrile convulsion

\section{Methodology}

Aim: To assess serum Iron and Zinc status in febrile seizures.

\section{Objectives of Study:}

1. To determine the hemoglobin, hematocrit, serum ferritin, peripheral smear, serum iron and serum zinc level in children with febrile seizure.

2. To compare hemoglobin, hematocrit, serum ferritin, peripheral smear, serum iron and serum zinc levels in febrile seizure and children without seizures as control group. 


\section{Inclusion Criteria:}

Children between age group of 6months-6 years with fever and seizures fitting into the following criteria:

1. Generalized tonic clonic type

2. Duration of $10-15 \mathrm{~min}$

3. Core temperature of 39 degrees centigrade

4. Brief period of post ictal drowsiness

5. One episode in 24 hours

6. no neurological deficits

7. cause of fever outside the central nervous system

8. First seizure or subsequent seizure.

\section{Exclusion Criteria:}

1. Previous history of established non febrile seizures.

2. Previous history of developmental delay and neurological deficits.

3. Central nervous system infections (meningitis, encephalitis), electrolyte imbalance, hereditary metabolic disorders, and also neurological and structural brain problems.

4. Seizures lasting for more than 20 minutes.

5. Focal seizures.

Study Design:

Prospective, Analytical, Case - Control study. The study is planned as a case control study.

\section{Source of Data}

The proposed study was a hospital based case control study consisting of Infants and children aged between 6 months to 5 years. They were evaluated at Department of Pediatrics, JUSTICE K.S.HEGDE CHARITABLE HOSPITAL, Mangalore during the term between October 2011 to October 2012.

\section{Method of Collection of Data}

Sample size: 100 cases meeting the criteria are included for the present study and are randomized equally into two groups: 50 cases and 50 controls.

Sampling Method: Simple Convenient sampling.

Selection of control: The control group included the age and weight matched children suffering from a febrile illness without seizures, such as urinary tract infection, gastroenteritis and respiratory tract infection, coming to KS hedge charitable hospital.

Simple convenient sampling was done based on inclusion and exclusion criteria. Cases and controls were matched for age and weight . The sample size included 50 cases and 50 controls, who came to K S hedge charitable hospital (both outpatient and inpatient). The group 1, had of children with febrile seizure and the group 2 had children with febrile illness without seizure.

Demographic data, seizure details, nature of febrile illness, complete developmental history, family history of epilepsy / febrile seizures, temperature at admission, general examination, Systemic examination and nutritional status will be recorded( IAP weight for age classification was used to grade protein energy malnutrition) including the final diagnosis were recorded.

Estimation of hemoglobin and hematocrit were done by auto analyzers.

Serum ferritin levels were measured using a Ferritin quantitative enzyme immunoassay test kit, which is based on a solid phase enzyme linked immunosorbent assay. The assay system utilizes one ferritin antibody for solid phase (microliter wells) immobilization and another mouse monoclonal anti-ferritin antibody in the antibody enzyme (horseradish peroxidase) conjugate solution. The test sample is allowed to react simultaneously with the antibodies, resulting in ferritin molecules being sandwiched between the solid phase and enzyme linked antibodies. After 60 min incubation at room temperature, the wells are washed with water to remove unbound labeled antibodies. A solution of TMB is added and incubated for $20 \mathrm{~min}$, resulting in the development of a blue color. The color development is stopped with the addition of $2 \mathrm{~N} \mathrm{HCL}$, and the color is changed to yellow and measured spectrophotometrically. At $450 \mathrm{~nm}$, the concentration of ferritin is directly proportion to the color intensity of the test sample.

Serum iron levels were estimated using Bathophenanthroline method, principle being Iron in the serum is present as $\mathrm{Fe}^{+++}$bound to transferring. In the assay, the proteins are precipitated and consequently the iron $\left(\mathrm{Fe}^{+}\right)$bound to ferritin is released by mild acid treatment. The iron thus released is reduced to $\left(\mathrm{Fe}^{2+}\right)$ by reducing agents. $\left(\mathrm{Fe}^{2+}\right)$ in turn reacts with Bathophenanthroline to form pink color complex whose intensity can be measured at $535 \mathrm{~nm}$. Peripheral smears were analyzed under light microscopy. 
Serum Zinc was measured by Calorimetric method, which is based on the principle that Zinc in alkaline medium reacts with nitro-PAPS to form a purple coloured complex. Intensity of the complex formed is directly proportional to the amount of Zinc present in the sample.

Anemia was be defined as, when one of the following is present: $\mathrm{Hb}<11 \mathrm{~g} / \mathrm{dl}$ based on WHO criteria for age, HCT level $<33 \%$ based on WHO criteria for age, serum iron concentration of $<22 \mu \mathrm{g} / \mathrm{dl}$, Serum ferritin less than 12 microgram/dl and Peripheral smear showing Microcytic hypochromic anemia. Since serum ferritin is acute phase reactant and its level is increased in any inflammatory conditions, in presence of fever a higher cut-off value of serum ferritin (30 microgram/dl) will be taken. Zinc level 70-120 $\mu \mathrm{g} / \mathrm{dL}$ will be considered as a normal range, and anything below $70 \mu \mathrm{g} / \mathrm{dL}$ will be considered as hypozinconemia.

Statistical method used:

Percentages, the arithmetic mean, the standard deviation, Chi-square test were employed using SPSS for Windows software (version 16.0). P-value $<0.05$ was considered statistically significant. The frequencies procedure was used for graphical displays that were useful for describing many types of variables. The cross tabs procedure was used to measure the association for two-way tables. The Independent samples ' $t$ ' test procedure was used to compare two groups of children.

\section{Results And Discussion:}

The following results were made from the study. The study group consisted of 50 cases and 50 controls. The study results were analyzed using appropriate statistical methods and compared with the previous studies.

\section{Gender Distribution among Cases and Controls}

Table 1: Gender distribution of the cases and Controls

\begin{tabular}{|c|c|c|}
\hline \multirow{2}{*}{} & \multicolumn{2}{|c|}{ Mean } \\
\cline { 2 - 3 } & $\begin{array}{c}\text { Cases } \\
\mathrm{n}(\%)\end{array}$ & $\begin{array}{c}\text { Controls } \\
\mathrm{n}(\%)\end{array}$ \\
\hline Males & $39(78)$ & $31(62)$ \\
\hline Females & $11(22)$ & $19(38)$ \\
\hline
\end{tabular}

In the present study, $78 \%$ of the cases were Males and 11\% were females. Among the 50 controls, $31 \%$ were males and $19 \%$ of them were females.

Figure 5: Gender distribution of the cases and controls

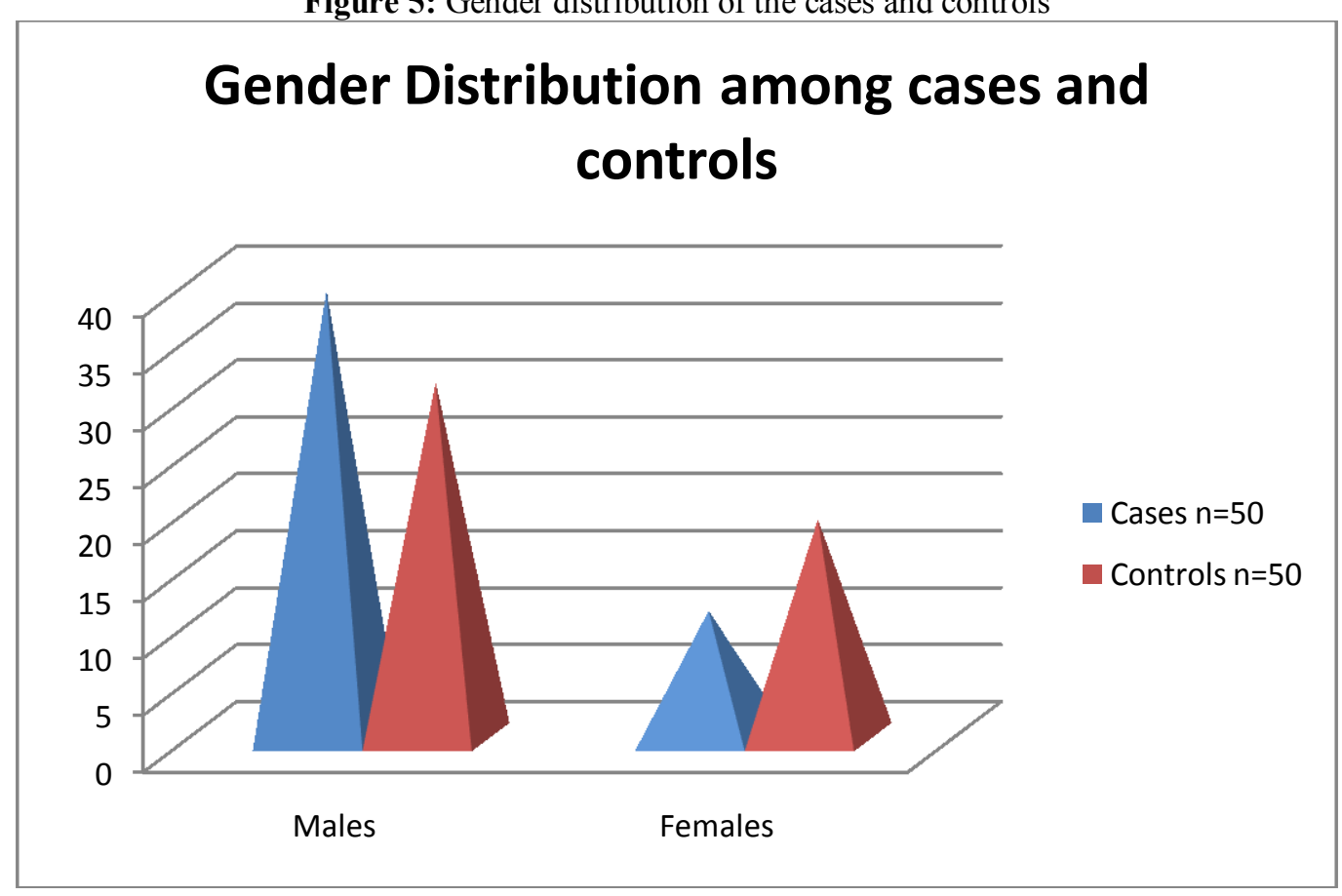


2. Type of Seizures among Cases:

Figure 6: Type of seizures among cases:

\section{Type of seizures among Cases}

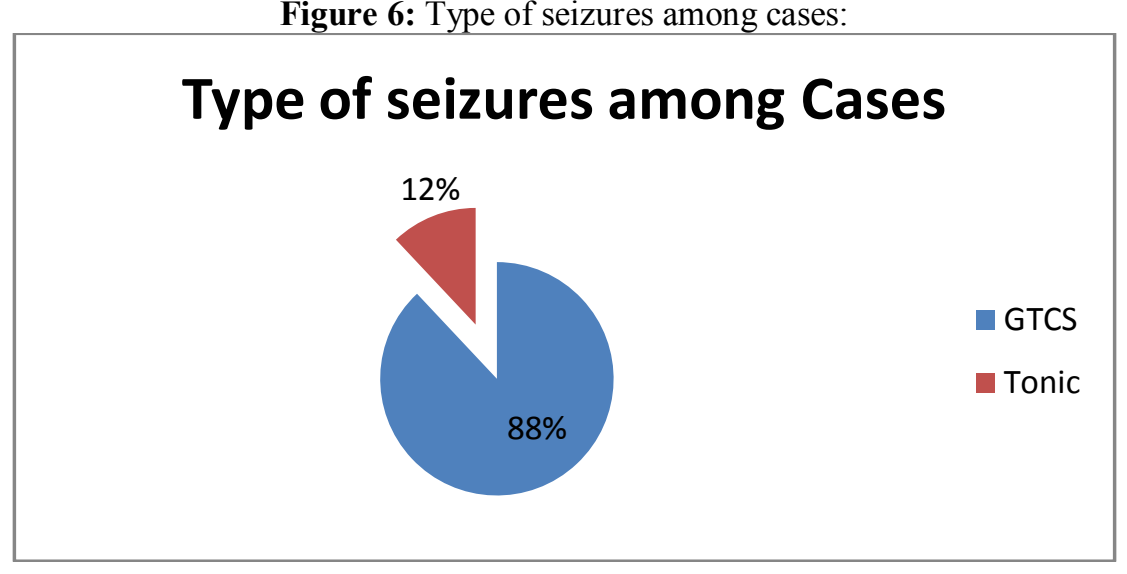

In the present study, $88 \%$ of the 50 cases had GTCS type of seizures and $12 \%$ had tonic type of seizures.

3. Episode of seizure

Figure 7: Episode of seizure among cases:

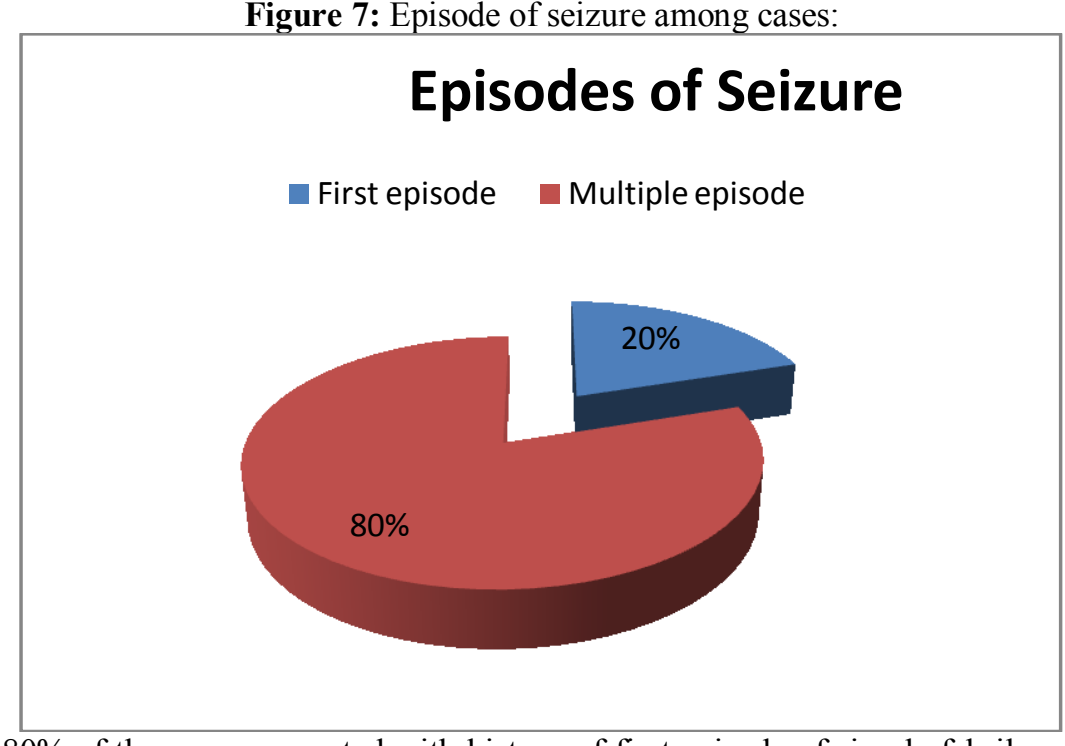

Among 50 cases $80 \%$ of the cases presented with history of first episode of simple febrile seizures and the rest i.e. $20 \%$ presented with history of multiple episodes of febrile seizures in the past.

4. Family history of febrile seizures among cases

Figure 8: Family history of febrile seizures

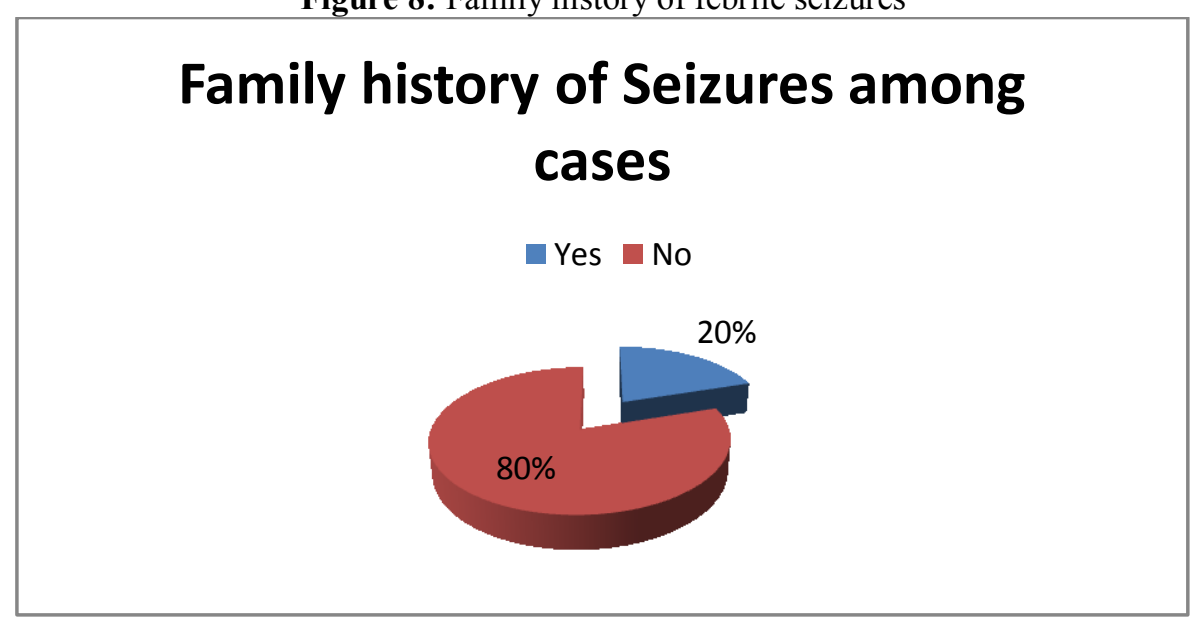

In the present study, $20 \%$ of the 50 cases presented with history of febrile seizures in the family. 
5. Socio economic status among cases and controls

Figure 9: Socioeconomic status among cases and controls

\title{
Socio economic status Among Cases and Controls
}

\author{
- Cases $\mathrm{n}=50 \quad$ Controls $\mathrm{n}=50$
}

50

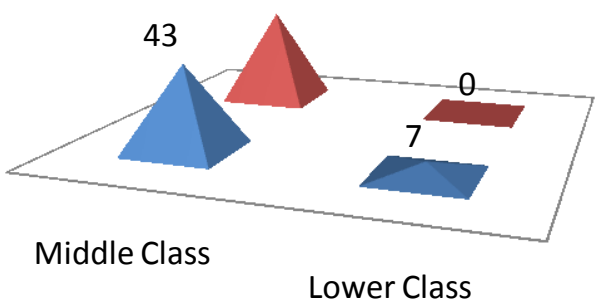

Among the 50 cases, 43 of them belonged to middle class and 7 belonged to lower class. All the 50 controls belonged to the middle class based on modified Kuppuswamy classification.

6. Mean temperature in cases and controls

Table 2: Mean temperature in cases and controls

\begin{tabular}{|l|c|c|c|}
\hline \multirow{2}{*}{} & \multicolumn{2}{|c|}{ Mean \pm SD } & \\
\cline { 2 - 4 } & $\begin{array}{c}\text { Cases } \\
\mathrm{n}=50\end{array}$ & $\begin{array}{c}\text { Controls } \\
\mathrm{n}=50\end{array}$ & P value \\
\hline Temperature in Fahrenheit & $100.67 \pm 0.63$ & $100.24 \pm 0.84$ & 0.088 \\
\hline
\end{tabular}

Figure 10: Mean temperature in cases and controls

\section{Mean temperature in Cases and Controls}

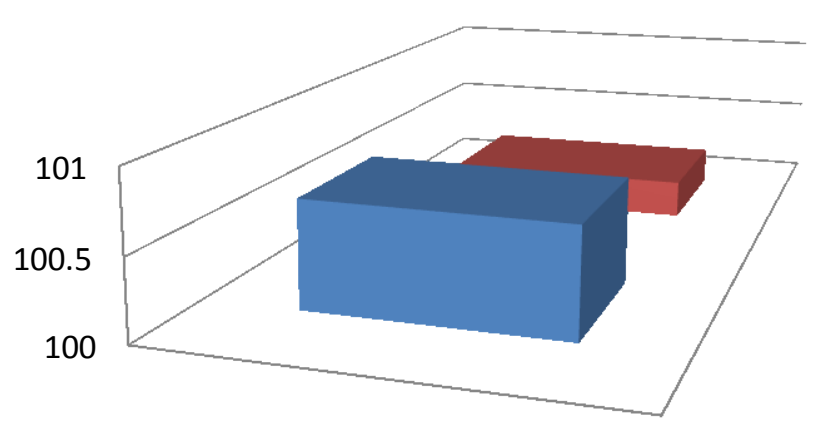

Temperature in fahrenheit

Cases Controls

Mean temperature among cases was $100.67 \pm 0.63$ degree Fahrenheit and among controls was $100.24 \pm 0.84$ degree Fahrenheit.

\section{Age and weight distribution}

Table 3: Age and weight distribution among cases and controls

\begin{tabular}{|l|c|c|c|}
\hline \multirow{2}{*}{} & \multicolumn{2}{|c|}{ Mean \pm SD } & \\
\cline { 2 - 4 } & $\begin{array}{c}\text { Cases } \\
\mathrm{n}=50\end{array}$ & $\begin{array}{c}\text { Controls } \\
\mathrm{n}=50\end{array}$ & P value \\
\hline Age in months & $22.14 \pm 13.2$ & $21 \pm 14.08$ & 0.58 \\
\hline Weight in Kgs & $10.13 \pm 2.4$ & $9.94 \pm 2.5$ & 0.58 \\
\hline
\end{tabular}


Figure 11: Age and weight distribution among cases and controls

\section{Age and Weight distribution in cases and controls}

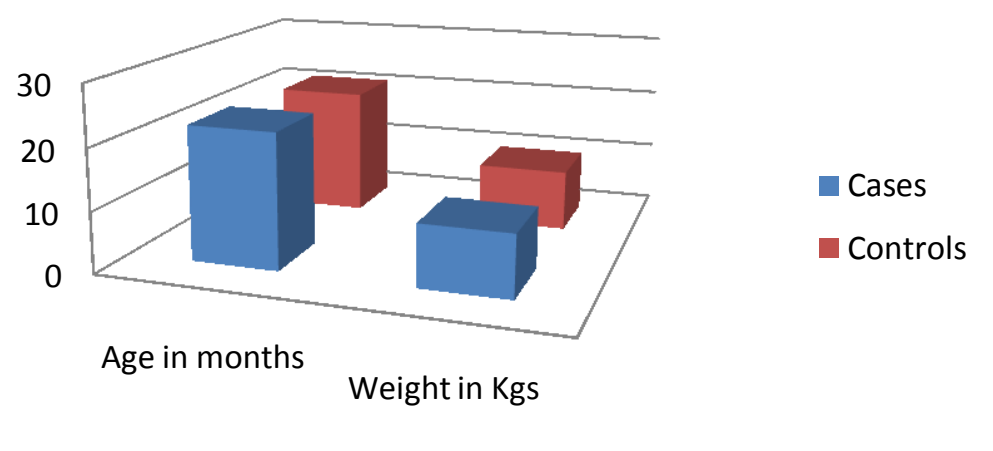

In the present study, cases and controls were age and weight matched. Mean age among cases was $22.14 \pm 13.2$ months and $21 \pm 14.08$ months among controls. Mean weight among cases was $10.13 \pm 2.4 \mathrm{kgs}$ and $9.94 \pm 2.4 \mathrm{kgs}$ among controls.

8. Grades of Protein energy malnutrition Based in IAP classification

Figure 12: Grades of Protein energy malnutrition among cases and controls

\section{Grades of PEM among Cases and Controls Based on IAP Classification}

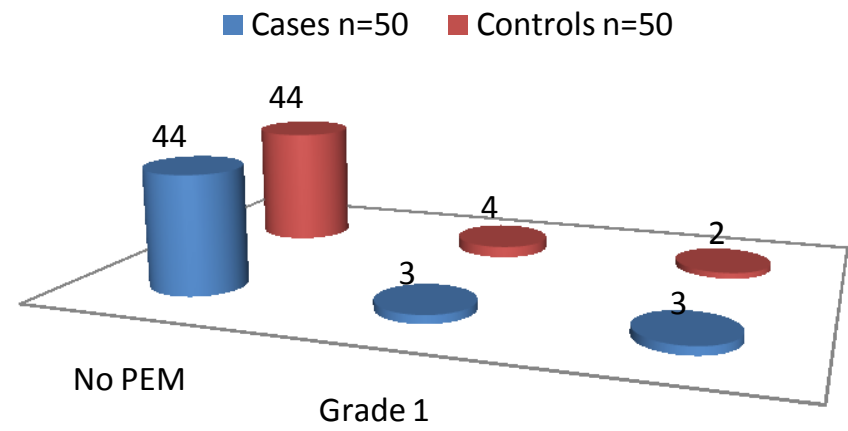

Grade 2

Among 50 cases, $88 \%$ of them had no malnutrition, $5 \%$ of them had grade1 malnutrition and remaining $6 \%$ had grade 2 malnutrition. Out of 50 controls, $88 \%$ of them had no malnutrition, $8 \%$ had grade 1 malnutrition and remaining $2 \%$ had grade 2 malnutrition.

\section{Diagnosis among cases and controls}

Table 4: Mean of different diagnosis among cases and controls

\begin{tabular}{|c|c|c|}
\hline \multirow{2}{*}{} & \multicolumn{2}{|c|}{ Mean } \\
\cline { 2 - 3 } & Cases n(\%) & Controls n(\%) \\
\hline URTI & $22(44)$ & $26(52)$ \\
\hline LRTI & $9(18)$ & $5(10)$ \\
\hline Acute Gastroenteritis & $12(24)$ & $5(10)$ \\
\hline Malaria & $1(2)$ & $4(8)$ \\
\hline Viral Fever & $6(12)$ & $10(20)$ \\
\hline Total & $50(100)$ & $50(100)$ \\
\hline
\end{tabular}


Figure 13: Mean of different diagnosis among cases and controls

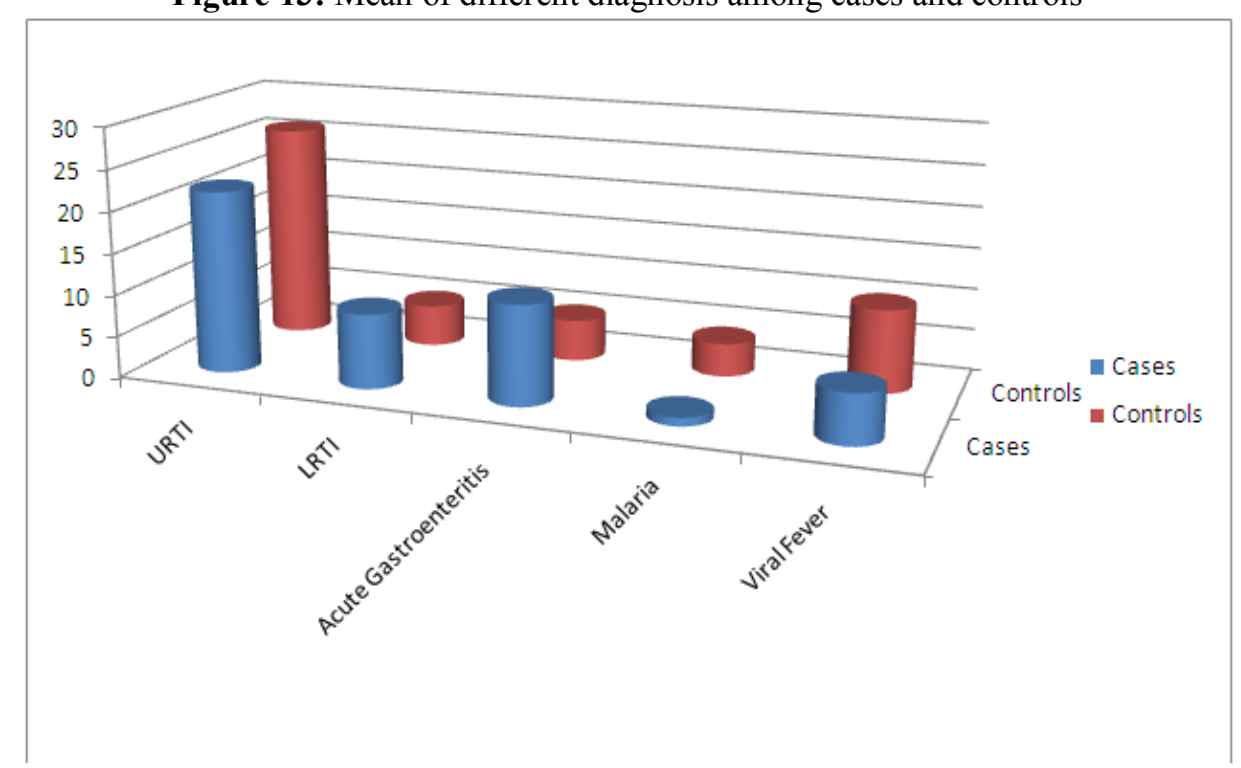

Of the 50 cases in the present study 44\% had URTI, 18\% had LRTI, 24\% had Acute Gastroenteritis, 2\% had Malaria and $12 \%$ had viral fever respectively. Among the controls 52\% had URTI, 10\% had LRTI, $10 \%$ had Acute Gastroenteritis, $8 \%$ had Malaria and $20 \%$ had viral fever respectively

\section{Peripheral smear in Cases and controls}

Table 5: P smears among cases and controls.

\begin{tabular}{|c|c|c|c|}
\hline & \multicolumn{2}{|c|}{ Mean } & \multirow{2}{*}{ P Value } \\
\cline { 2 - 3 } & Cases n(\%) & Controls n(\%) & \multirow{2}{*}{0.001} \\
\hline Normal P Smear & $29(58)$ & $43(86)$ & \\
\hline Abnormal P Smear * & $21(42)$ & $7(14)$ & \\
\hline Total & $50(100)$ & $50(100)$ & \\
\hline
\end{tabular}

Figure 14: Peripheral smears in cases and controls

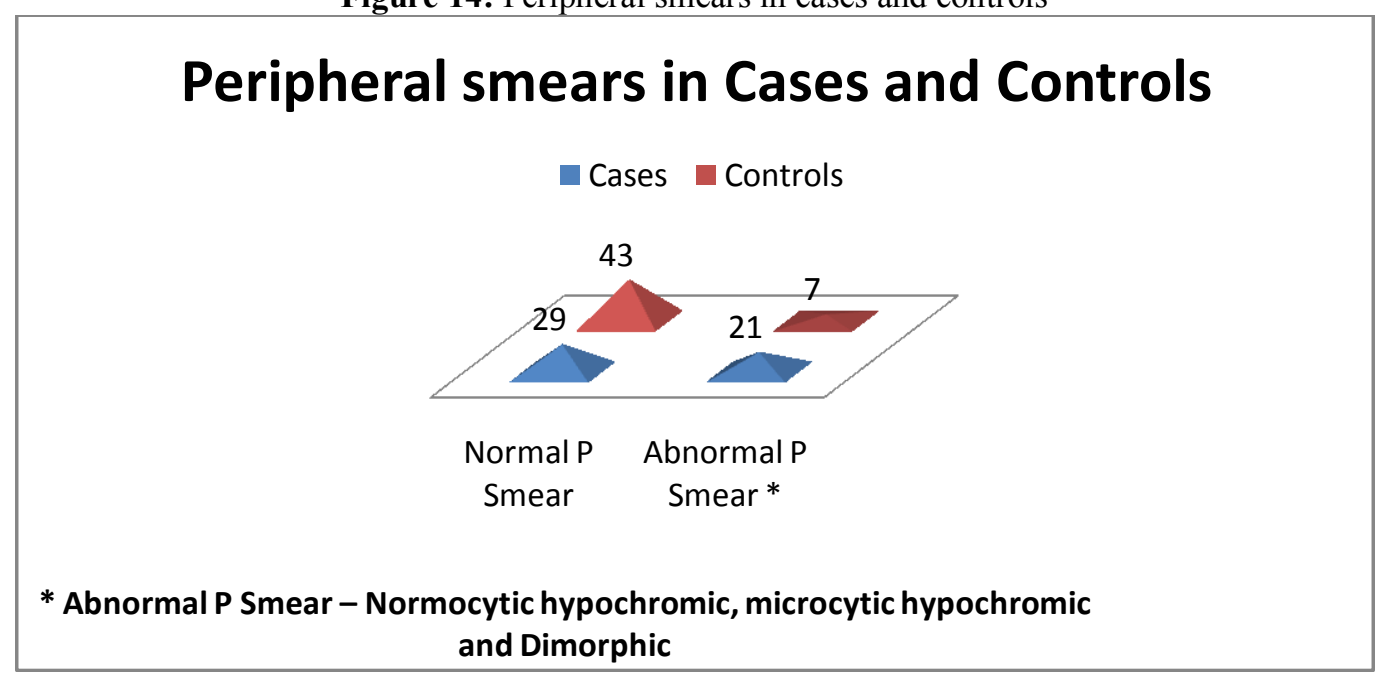

In the present study of the 50 cases, $58 \%$ of them had normal peripheral smear and the rest $42 \%$ had abnormal smear, compared to $86 \%$ of the 50 controls having normal peripheral smears and $14 \%$ abnormal peripheral smears. Chi square test value was 9.72 , with a $\mathrm{p}$ value of 0.001 , which was statistically significant. 
11. Haemoglobin levels among cases and controls

Table 6: Mean Haemoglobin levels among cases and controls

\begin{tabular}{|c|c|c|c|c|c|}
\hline \multirow{2}{*}{} & \multicolumn{2}{|c|}{ Mean $\pm \mathrm{SD}$} & \multirow{2}{*}{ P value } & $\begin{array}{c}\text { 95\% Confidence Interval of the } \\
\text { Difference }\end{array}$ \\
\cline { 2 - 5 } & Cases & Controls & Lower & \multirow{2}{*}{ Upper } \\
\cline { 2 - 5 } $\begin{array}{c}\text { hemoglobin in } \\
\text { mg/dl }\end{array}$ & $\mathrm{n}=50$ & $11.11 \pm 0.7$ & 0.6 & -0.79973 & -0.07227 \\
\hline
\end{tabular}

Figure 15: Mean Haemoglobin levels among cases and controls

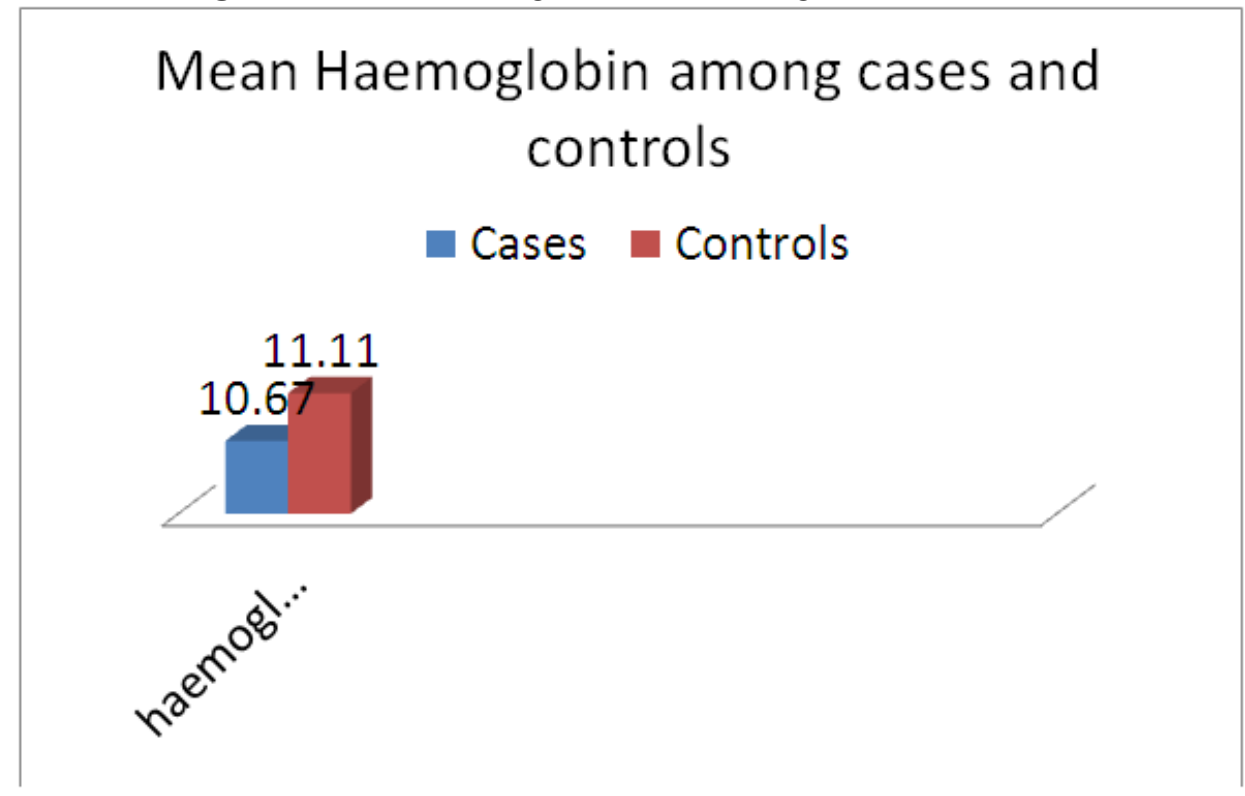

In the present study, mean Haemoglobin level among cases was $10.67 \pm 1 \mathrm{mg} / \mathrm{dl}$ and $11.11 \pm 0.7 \mathrm{mg} / \mathrm{dl}$ among controls with a $\mathrm{p}$ value of 0.6 .

12. Packed cell volume among cases and controls

Table 7: Mean Packed cell volume among cases and controls

\begin{tabular}{|c|c|c|c|c|c|}
\hline \multirow{2}{*}{} & \multicolumn{2}{|c|}{ Mean $\pm \mathrm{SD}$} & \multirow{2}{*}{ P value } & \multicolumn{2}{|c|}{$\begin{array}{c}\text { C5\% Confidence Interval of } \\
\text { the Difference }\end{array}$} \\
\cline { 2 - 3 } & $\begin{array}{c}\text { Cases } \\
\mathrm{N}=50\end{array}$ & $\begin{array}{c}\text { Controls } \\
\mathrm{N}=50\end{array}$ & & Lower & Upper \\
\hline Packed Cell volume & $31.6 \pm 2.7$ & $32.05 \pm 1.7$ & 0.108 & -1.28781 & 0.52381 \\
\hline
\end{tabular}

Figure 16: Mean Packed cell volume among cases and controls

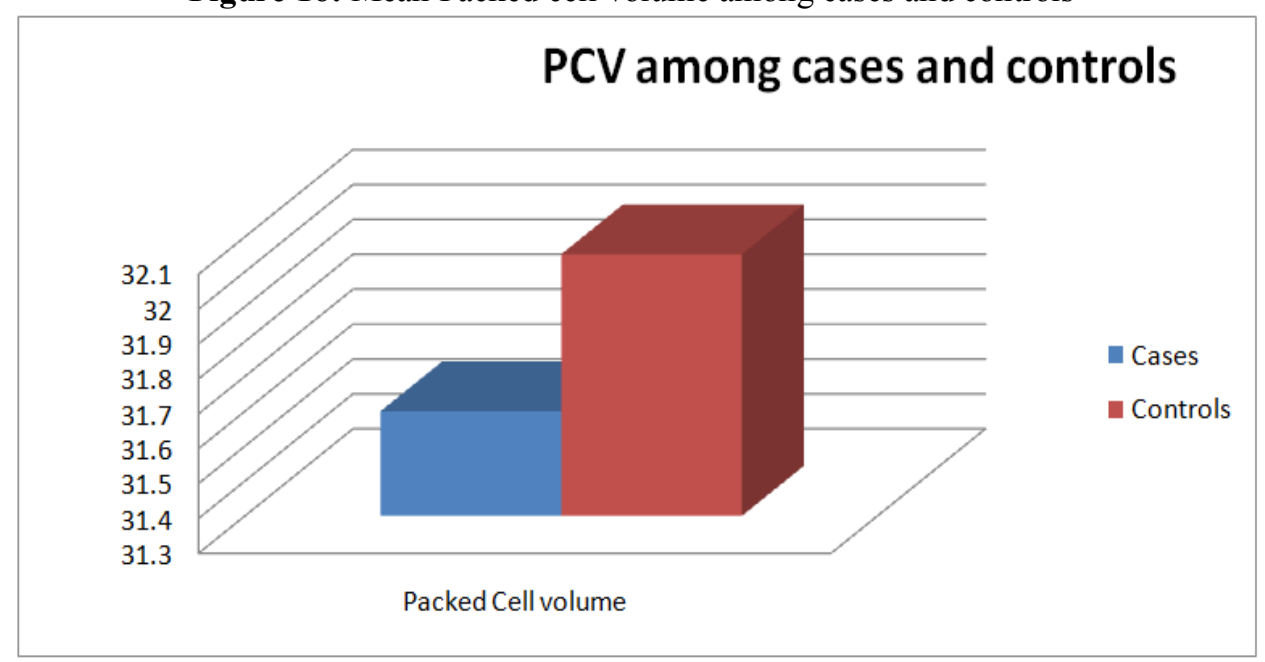


In the present study, mean PCV level among cases was $31.6 \pm 2.7 \%$ and $32.05 \pm 1.7 \%$ among controls with a $\mathrm{p}$ value of 0.5

13. Iron levels among cases and controls

Table 8: Mean Iron levels among cases and controls

\begin{tabular}{|c|c|c|c|c|c|}
\hline \multirow{2}{*}{} & \multicolumn{2}{|c|}{ Mean $\pm \mathrm{SD}$} & \multirow{2}{*}{ P value } & \multicolumn{2}{|c|}{$\begin{array}{c}\text { 95\% Confidence Interval of the } \\
\text { Difference }\end{array}$} \\
\cline { 2 - 3 } \cline { 5 - 5 } & Cases $\mathrm{n}=50$ & Controls $\mathrm{n}=50$ & & Lower & Upper \\
\hline Iron in $\mu \mathrm{g} / \mathrm{dl}$ & $90.12 \pm 23.64$ & $143.54 \pm 21.85$ & 0.868 & -62.4585 & -44.3854 \\
\hline
\end{tabular}

Figure 17: Mean Iron levels among cases and controls

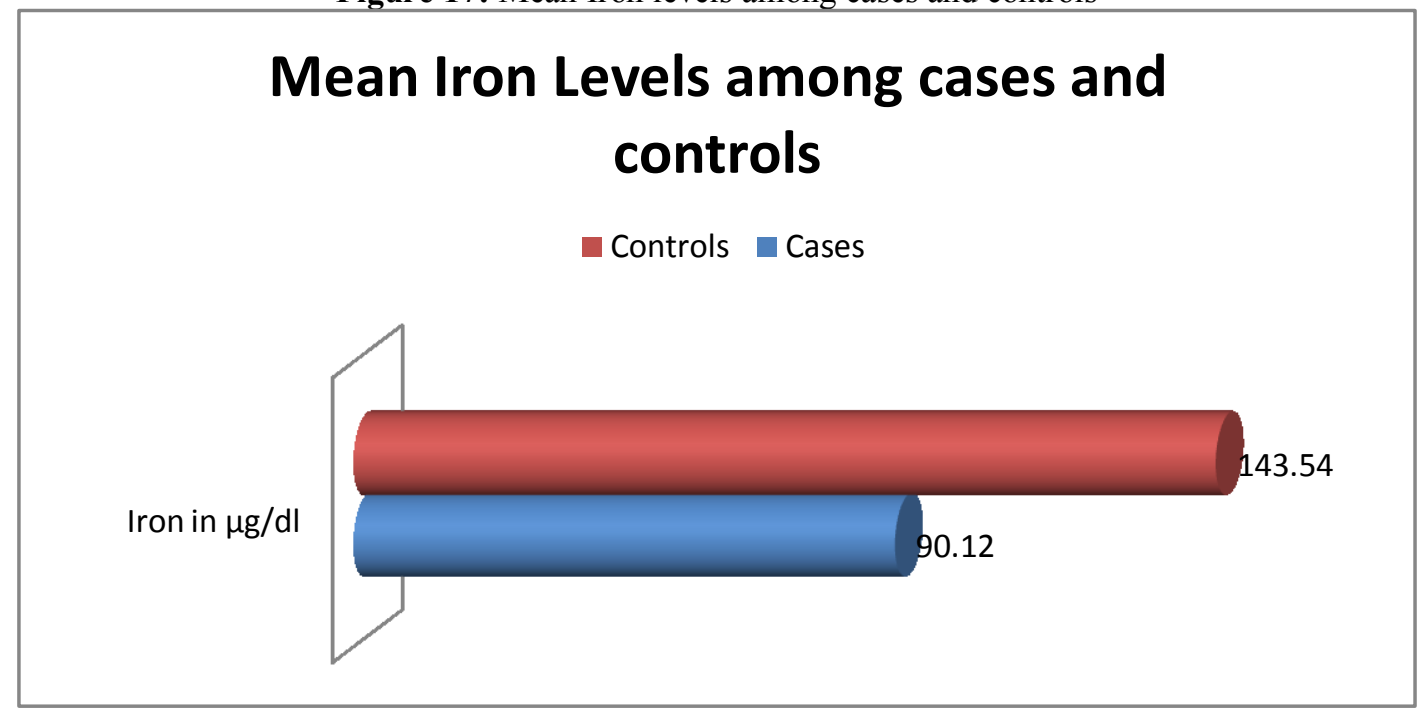

In the present study, mean Iron levels were $90.12 \pm 23.64 \mu \mathrm{g} / \mathrm{dl}$ among the cases and $143.54 \pm 21.85 \mu \mathrm{g} / \mathrm{dl}$ among the controls with a p value of 0.868 .

\section{Ferritin levels among Cases and Controls}

Table 9: Mean ferritin levels among cases and controls

\begin{tabular}{|c|c|c|c|c|c|}
\hline \multirow{2}{*}{} & \multicolumn{2}{|c|}{ Mean $\pm \mathrm{SD}$} & \multirow{2}{*}{ P value } & \multicolumn{2}{c|}{$\begin{array}{c}\text { 95\% Confidence Interval of the } \\
\text { Difference }\end{array}$} \\
\cline { 2 - 3 } & Cases & Controls & & Lower & Upper \\
\cline { 2 - 5 } & $13.371 \pm 3.2480$ & $10.917 \pm 2.875$ & 0.868 & 11.86888 & 37.211 \\
\hline Ferritin in $\mu \mathrm{g} / \mathrm{dl}$ & &
\end{tabular}

Figure 18: Mean ferritin levels among cases and controls

\section{Mean Ferritin levels among cases and Controls}

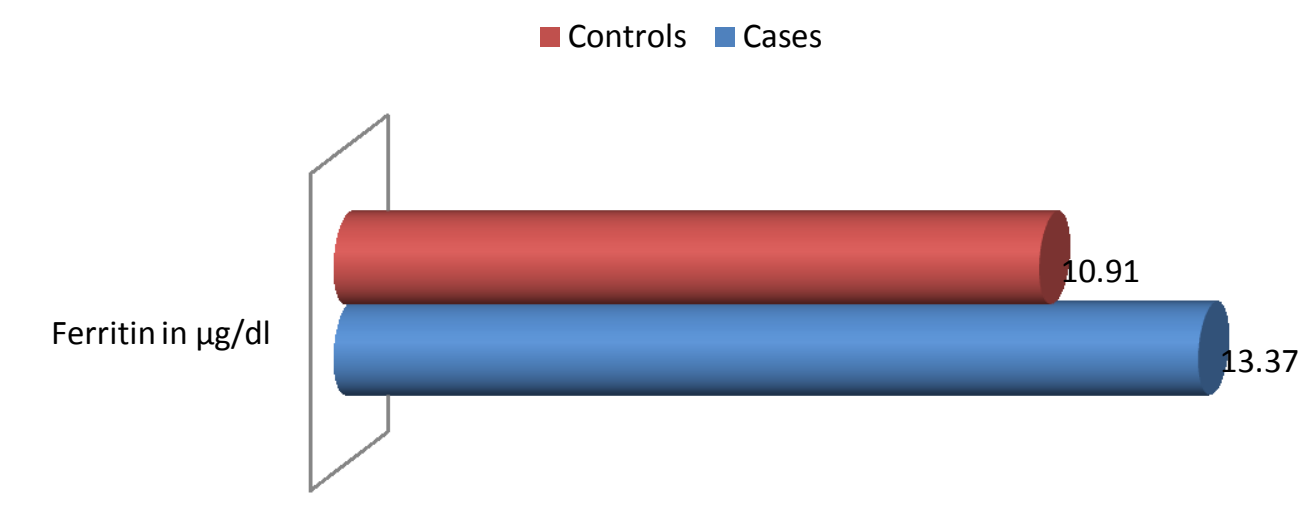


In the present study, mean Ferritin levels were $13.371 \pm 3.2480 \mu \mathrm{g} / \mathrm{dl}$ among the cases and $10.917 \pm 2.875$ $\mu \mathrm{g} / \mathrm{dl}$ among the controls, with a $\mathrm{p}$ value of 0.868 .

\section{Zinc levels among cases and controls}

Table 10: Mean Zinc levels among cases and controls

\begin{tabular}{|c|c|c|c|c|c|}
\hline & Mean \pm SD & & \multirow{2}{*}{ P value } & \multicolumn{2}{|c|}{$95 \%$ Confidence Interval of the Difference } \\
\cline { 2 - 3 } \cline { 5 - 6 } & Cases & Controls & & Lower & Upper \\
\hline Zinc in $\mu \mathrm{g} / \mathrm{dl}$ & $132.04 \pm 14.7$ & $155.09 \pm 17.57$ & 0.264 & -29.486786 & -16.622378 \\
\hline
\end{tabular}

Figure 19: Mean Zinc levels among cases and controls

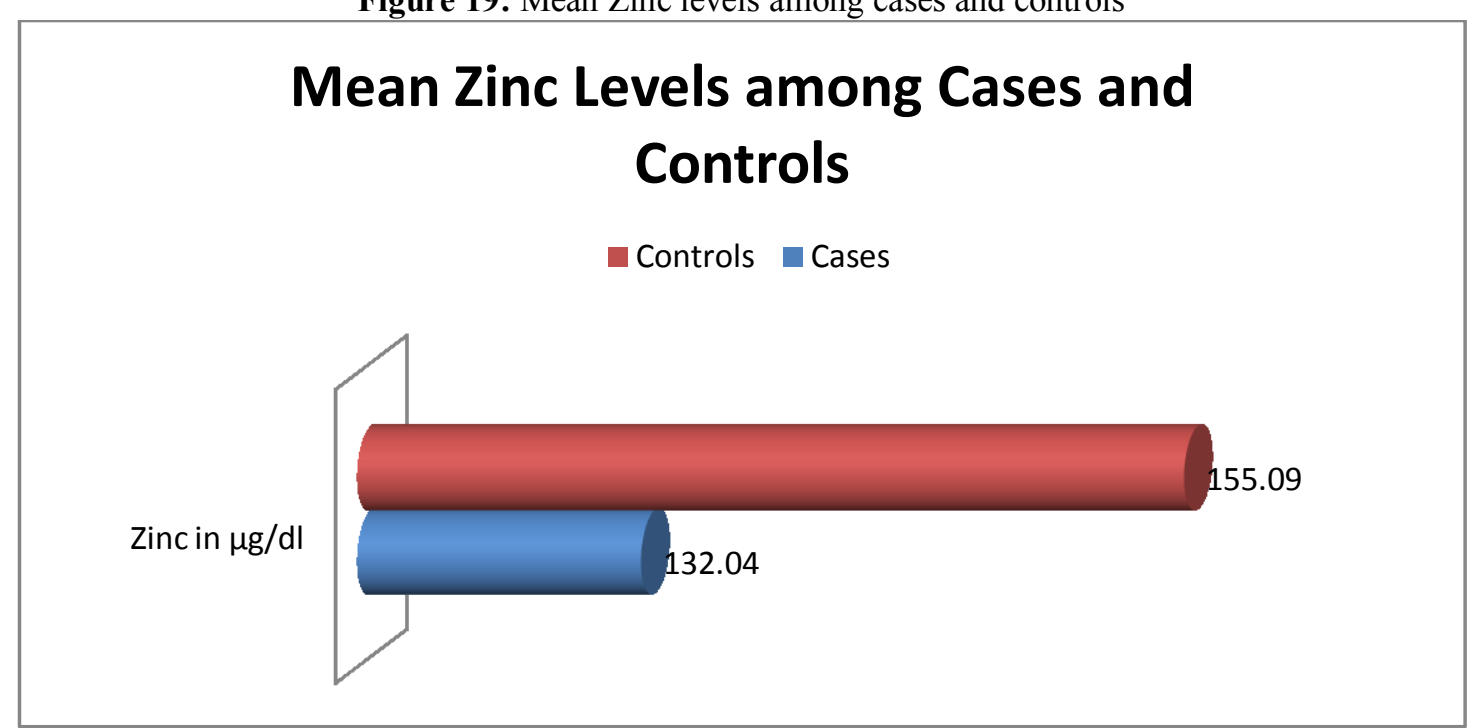

In the present study, mean Zinc levels were 132.04 $\pm 14.7 \mu \mathrm{g} / \mathrm{dl}$ among the cases and $155.09 \pm 17.57 \mu \mathrm{g} / \mathrm{dl}$ among the controls, with a $\mathrm{p}$ value of 0.264 .

\section{Discussion}

Convulsions or seizures are one of the important pediatric health problems in developing and developed countries.

Febrile seizures are the most common seizure disorder in childhood, affecting $2 \%$ to $5 \%$ of children between the ages of 6 and 60 months. It is generally believed that an FS is an age-dependent response of the immature brain to fever. This postulation is supported by the fact that most $(80-85 \%)$ febrile seizures occur between 6 months and 3 years of age, with the peak incidence at 18 months. ${ }^{6,7,8}$ Although the mechanism of this increased susceptibility is unclear, animal models suggest that there is enhanced neuronal excitability during the normal brain maturation. ${ }^{17}$ The iron deficiency and zinc deficiency is identified as one of the risk factors for febrile seizure. The objective of the study is to determine iron deficiency and hypozinconemia as a risk factor for febrile seizure. One-hundred cases meeting the criteria were included for the present study and are randomized equally into two groups: 50 cases and 50 controls which were age and weight matched.

Both cases and controls were evaluated with following parameters. Hemoglobin, hematocrit, peripheral smear, serum ferritin, Serum Iron and Serum Zinc were measured and compared using statistical methods.

\section{Age Distribution}

In the present study, Mean age among cases was 22.14 months and among controls was 21 months.

In the study done by Hartfield et al., ${ }^{25}$ reported maximum cases were in the age group less than 24 months and mean age was 17.9 months. In the study done by Leela Kumara et al., the found the $55.8 \%$ of cases and $56.5 \%$ of controls were in the age group less than 17 months. Alberto Romero Guzman et al., in there study found $55 \%$ prevalence among 6 months to 24 months.

Table 11: Comparison of age distribution with other studies

\begin{tabular}{|c|c|c|}
\hline Sl no & Study & Mean age in months \\
\hline 1 & Alfredo Piscane et al & 15 \\
\hline 2 & Vasvani RK et al & 18 \\
\hline 3 & Waruiru C et al & 18 \\
\hline 4 & Azhar S Daoud et al & 22.97 \\
\hline 5 & Naveed-ur-Rehmann et al & 22.97 \\
\hline 6 & Nelson and Ellenberg & 18 \\
\hline
\end{tabular}




\begin{tabular}{|c|c|c|}
\hline 7 & Amir Salari et al & 39 \\
\hline 8 & Present study & 22.14 \\
\hline
\end{tabular}

\section{Sex distribution of cases}

In the present study there was male preponderance. Out of 50 cases 39 (78 \%) were male and $11(22 \%)$ were female. Male to female ratio was 2.3:1. Regardless of the era of the study or particulars of the design; boys have consistently emerged with higher frequency of febrile seizures. Incidence ratios of boys: girls have ranged from 1.1:1 to 2:1 (Nelson and Ellenberg; Hauser; Forsgren et al.) However present study finding are in contrast to another set of large studies by Yerushalmy et al, 1969; Verity et al, 1985 who found no sex difference. Amir Salari also found no gender difference between cases and controls. NCPP study showed male predilection only among black population (Nelson and Ellenberg). Whether there is a biological basis for the gender-specific differences in febrile seizure susceptibility, or whether boys just contract more fevers and therefore are at greater risk, is currently not established.

Table 12: Comparison of sex distribution with other studies

\begin{tabular}{|c|c|c|}
\hline Studies & Gender & Percentage $\%$ \\
\hline Present study & Male & 58 \\
\hline Leelakumari et al. $^{31}(2011)$ & Male & 57.35 \\
\hline Hartfield et al. $^{24}(2009)$ & Male & 53.33 \\
\hline Azhar S. Daoud et al. ${ }^{21}(2002)$ & Male & 62.5 \\
\hline Alberto Romero Guzman et al. ${ }^{177}(2005)$ & Male & \\
\hline
\end{tabular}

Family history

Family history is important while evaluating epilepsy patients because many epileptic syndromes have a familial predisposition and some may possibly have an autosomal dominant pattern of inheritance. ${ }^{48}$ In the present study, $10(20 \%)$ cases had family history of febrile seizure.

Table 13: Comparison of family history with other studies

\begin{tabular}{|c|c|c|}
\hline Studies & No. & Percentage (\%) \\
\hline Present Study $^{21}(2002)$ & 10 & 20 \\
\hline Azhar S Daoud et al. $^{2}{ }^{177}(2005)$ & 9 & 18 \\
\hline Alberto Romero Guzman et al. $^{31}$ & 4 & 26 \\
\hline Leelakumari et al. ${ }^{31}(2011)$ & 40 & 10 \\
\hline
\end{tabular}

\section{Socioeconomic status}

India being a developing country has largest number of people living under poor socioeconomic class. In present study, 43 of them belonged to middle class and 7 belonged to lower class. All the 50 controls belonged to the middle class based on modified Kuppuswamy classification.

\section{Fever Etiology}

Upper respiratory tract infection is the commonest trigger of febrile seizure in present group of children and no statistical difference could be made out with the control group, as per different etiology. This is in keeping with Nelson and Ellenberg (1978), Millichap et al(2006) and Kyong KL et al. Chevrie and Aicardi et al (1975) reported URTI in $72 \%$ of the cases and Azhar S Daoud et al from Jordan, reported URTI as the commonest triggering factor, diagnosed in $53 \%$ of cases, which is comparable to present study. However the etiology of febrile convulsion varies from country to country due to different infection profile. Farwell et al had shown that up to one-third of the cases of febrile convulsion the cause of fever is unknown.

\section{Comparison of Hemoglobin with various other studies}

The definition of anaemia varies by sex and age. The most commonly used definitions of anaemia come from the Centres for Disease Control and Prevention (CDC) and the World Health Organization (WHO).Among the various causes of anaemia resulting from lack of sufficient iron for synthesis of haemoglobin is the most common hematologic disease of infancy and childhood. It is estimated that $30 \%$ of the global population suffers from iron-deficiency anaemia; most of those affected live in developing countries. The incidence of iron deficiency anaemia among children 6 months to 59 months in India is $79 \%$. This includes $26 \%$ who are mild anaemic, $40 \%$ who are moderately anaemic and $3 \%$ suffer from severe anaemia (NFHS 3 conducted in 2006-06). In the present study, mean hemoglobin among cases was $10.17 \mathrm{mg} / \mathrm{dl}$ and among controls were 11.11, which is low for the age according to WHO standards. 
Table 14: Comparison of Hemoglobin with various other studies

\begin{tabular}{|c|c|}
\hline Study & $\mathrm{Hb}(\mathrm{gm} \%)$ \\
\hline Kobrinsky et al & $<11$ \\
\hline Pisacane et al & 10.5 \\
\hline Daoud et al & $<11$ \\
\hline Naveed-ur et al & $<10$ \\
\hline Vasvani et al & 9.4 \\
\hline Khalid N et al & $8.2-9.6$ \\
\hline Present study & $10.67 \pm 1$ \\
\hline
\end{tabular}

\section{Comparison of Serum iron with other studies:}

The serum iron concentration represents equilibrium between the iron entering and leaving the circulation. It reflects the balance between several factors, including iron absorbed, iron used for hemoglobin synthesis, iron released by red cell destruction and the size of iron stores. As a measure of iron deficiency, serum iron estimation can have some limitations because iron has a wide range of normal values that can vary significantly with age, sex, laboratory methodology there can be marked circadian changes (as much as 100 $\mu \mathrm{g} / \mathrm{dl}$ during the day) in iron level. In present study, there was variation of the iron level with FS and FI group i.e., mean iron levels were $90.12 \mathrm{mcg} / \mathrm{dl}$ and $143 \mathrm{mcg} / \mathrm{dl}$ in cases and controls respectively. Fever, was present in all patients in the both groups. Even though Iron levels are comparatively lower in FS group, the differences in iron level between the two groups cannot be explained by fever per se. Pisacane et al studied the serum iron level only, between 6- 24 months of age, where the level was low in febrile children. Bidabadi et al reported that the serum Iron level in febrile seizure was higher at a statistically insignificant level.

\section{Comparison of Serum ferritin with other studies}

Serum ferritin is an indicator of body stores of iron. Serum ferritin is reliable indicator which can be used to determine body stores of iron can be repeated whenever required. A serum ferritin level below $30 \mu \mathrm{g} / \mathrm{dl}$ is indicator of iron deficiency status. In the present study mean serum ferritin levels were $13.37 \mu \mathrm{g} / \mathrm{dl}$ and $10.917 \mu \mathrm{g} / \mathrm{dl}$, in cases and controls respectively. Under steady state conditions, the serum ferritin level correlates with total body iron stores; thus, the serum ferritin is the most convenient laboratory test to estimate iron stores.

Table 15: Comparison of Serum ferritin with other studies

\begin{tabular}{|c|c|}
\hline Study & PF $\mu \mathrm{g} / \mathrm{dl}$ \\
\hline Kobrinsky et al & $<20$ \\
\hline Pisacane et al & $<5$ \\
\hline Daoud et al & $<30$ \\
\hline Naveed-ur et al & $<10$ \\
\hline Vasvani et al & 31.9 \\
\hline Azhar S Daoud et al & $29.5 \pm 21.3$ \\
\hline Rajwanti K Vaswani et al & $<25$ \\
\hline Present study & $13.371 \pm 3.2480$ \\
\hline
\end{tabular}

Serum Zinc:

Zinc is a fundamental component of body enzymes that modulates CNS activities. CSF hypozinconemia activates N Methyl- D-aspartate receptors or disinhibits GABAergic action, thus resulting in febrile convulsion. In our study a low serum zinc level was found in patients with febrile convulsion as compared to the controls i.e.Mean Zinc levels were 132.04 and $155.09 \mathrm{mcg} / \mathrm{dl}$ among cases and controls respectively. Similar findings were noted by others. Papierkowski et al found that the mean serum concentration of magnesium and zinc were significantly lower in the children with febrile convulsion. In another study by Tutuncuoglu s et al, researchers have shown that children with febrile convulsion had significantly higher plasma IL. 1 beta and prostaglandin levels and lower serum zinc levels during the acute phase. They concluded that these changes may be responsible for the pathogenesis of febrile convulsion. In the present study mean zinc levels were comparatively lower in FS group compared to FI group, but however it was statistically insignificant.

\section{Conclusion}

The association between Iron and Zinc deficiency in febrile seizures has been studied before without any conclusive reports and this study was done for further confirmation.

1. $78 \%$ of the children in FS group were Males and $11 \%$ were females.

2. Male to female ratio was 2.3:1.

3. Mean age of the cases who presented with febrile seizures in the present study was 22.14 months.

4. Family history is important while evaluating epilepsy patients, $20 \%$ of the 50 cases had family history of febrile seizures in the present study. 
5. Upper respiratory tract infection is the commonest trigger of febrile seizure in present group of children.

6. Mean hemoglobin and PCV among the children who presented with febrile seizures were $10.17 \mathrm{mg} / \mathrm{dl}$ and $31.6 \pm 2.7 \%$ respectively, which are low for the age according to WHO standards.

7. $58 \%$ of the 50 cases had normal peripheral smear and the rest $42 \%$ had abnormal smear, compared to $86 \%$ of the 50 controls had normal peripheral smears and $14 \%$ abnormal peripheral smears, with a $p$ value of 0.001, which was statistically significant. Indicating anemia being more prevalent among children in FS group.

8. In present study, there was variation of the iron level with FS and FI group i.e., mean iron levels were 90.12 $\mathrm{mcg} / \mathrm{dl}$ and $143 \mathrm{mcg} / \mathrm{dl}$ in cases and controls respectively, which is within normal limits. But however Serum iron estimation can have some limitations because iron has a wide range of normal values that can vary significantly with age, sex, laboratory methodology and there can be marked circadian changes in iron level, therefore the above said values cannot be taken conclusive, but however the mean iron levels was low in FS group compared to children with FI alone.

9. A serum ferritin level below $30 \mu \mathrm{g} / \mathrm{dl}$ is indicator of iron deficiency status in the presence of infection. In the present study mean serum ferritin levels among children in FS group were $13.37 \mu \mathrm{g} / \mathrm{dl}$, which is below the normal limits.

10. In the present study, even though mean zinc levels being normal for the age, they were comparatively lower in FS group compared to FI group, but however it was statistically insignificant.

A follow up study of patients found to be iron and zinc deficient at the time of first febrile seizure to determine the incidence of subsequent febrile seizures after treatment for iron and zinc deficiency would be of great interest.

\section{Bibliography}

[1]. World Health Organization. Atlas: Epilepsy Care in the World. Geneva: World Health Organization; $2005: 91$.

[2]. Johnston MV. Seizure in childhood: febrile seizure. 17th ed. In: Nelson's text book of pediatrics, Behrman RE, Kliegman RM, Jenson HB, eds. Pennsylvania: Saunders; 2004. pp. 1994-5.

[3]. Murray CJL, Lopez AD. Global Comparative Assessment in the Health Sector; Disease Burden, Expenditures, and Intervention Packages. Geneva: World Health Organization; 1994.

[4]. Kinnier Wilson JV, Reynolds EH. Translation and analysis of a cuniform text forming part of a Babylonian treatise on epilepsy. Med Hist 1990;34:185-98.

[5]. Temkin O. The Falling Sickness. Baltimore: Johns Hopkins Press; 1945:380. 6. Hippocrates. The sacred disease. In: Hippocrates, Page TE, Capps E, Rouse WHD, eds. Cambridge, MA: Harvard University Press; 1967. 2:127-84.

[6]. Jackson JH. On epilepsy and epileptiform convulsions. In: Selected Writings of John Hughlings Jackson, Taylor J, ed. London: Hodder and Stoughton; 1931. 1. 8. Senanayake N, Roman GC. Epidemiology of epilepsy in developing countries. Bull WHO 1993;71(2):247-58.

[7]. Shah I, Deshmukh CT. Intramuscular midazolam vs intravenous diazepam for acute seizures. Indian J Pediatr 2005;72(8):667-70.

[8]. Verity CM, Butler NR, Golding J. Febrile convulsions in a national cohort followed up from birth I-Prevalence and recurrence in the first five years of life. Br Med J (Clin Res Ed) 1985;290:1307. 11. Forsgren L, Sidenvall R, Blomquist HK, Heijbel J. A prospective incidence study of febrile convulsions. Acta Paediatr Scand 1990;79:550-7.

[9]. Hauser WA. The prevalence and incidence of convulsive disorders in children. Epilepsia 1994;35:S1-6.

[10]. Vestergaard M, Obel C, Henriksen TB, Christensen J, Madsen KM, Ostergaard JR, et al . The Danish National Hospital Register is a valuable study base for epidemiologic research in febrile seizures. J Clin Epidemiol 2006;59:61-6.

[11]. Hackett R, Hackett L, Bhakta P. Febrile seizures in a South Indian district: Incidence and associations. Dev Med Child Neurol 1997;39:380-4.

[12]. Gourie-Devi M, Gururaj G, Satishchandra P, Subbakrishna DK. Prevalence of neurological disorders in Bangalore, India: A community-based study with a comparison between urban and rural areas. Neuroepidemiology 2004;23:261-8.

[13]. Berg AT. Are febrile seizures provoked by a rapid rise in temperature? Am J Dis Child 1993;147:1101-3.

[14]. Rantala H, Uhari M, Hietala J. Factors triggering the first febrile seizure. Acta Paediatr 1995;84:407-10.

[15]. Berg AT, Shinnar S, Shapiro ED. Risk factors for a first febrile seizure: a matched case-control study. Epilepsia 1995;36:334-41.

[16]. Bethune P, Gordon K, Dooley J, . Which child will have a febrile seizure? Am J Dis Child 1993;147:35-9.

[17]. Pisacane A, Sansone R, Impagliazzp N, Coppola A, Rolando P, D Apuzzo A, et al. Iron deficiency anemia and febrile convulsion; case control study in children under 2 years. BMJ 1996;313-43.

[18]. Daoud AS, Batieha A, Abu-Ekteish F, Gharaibeh N, Hijazi SAS. Iron status: A Possible risk factor for the first febrile seizure. Epilepsia 2002;43(7):740-3.

[19]. Auvichayapat P. J Med Assoca Thai 2004;87(8):970-1031.

[20]. Naveed-ur-Rehman, Billoo AG. Association between iron deficiency anemia and febrile seizures. J Coll Physicians Surg Park $2005 ; 15(6): 338-40$.

[21]. Hartifeld DS, Tan J, Yager JY, Rosychuk RJ, Spandy D, Haines C, Craig WR. The association between iron deficiency and febrile seizure in childhood. Clinical Pediatrics 2009;48(4):420-6.

[22]. Vaswani RK, Dharaskar PG, Kulkarni S, Ghosh K. Iron Deficiency as risk factor for first febrile seizure. Indian Pediatrics 2009 Sep 3.

[23]. Guyatt GH, Patterson C, Ali M, Singer J, Levine M, Turpie I, Meyer R. J Gen Intern 1990.

[24]. Guyatt GH, Oxman AD, Ali M, Willan A, Mcllroy W, Patterson C. Laboratory diagnosis of iron-deficiency anemia: an overview. J Gen Intern Med 1992 Mar-Apr;7(2):145-53.

[25]. Kis AM, Carnes M. Detecting iron deficiency in anemic patients with concomitant medical problems. J Gen Intern Med 1998 Jul;13(7):455-61.

[26]. Mittal, Marwaha N, Basu S, Mohan H, Kumar R. Evaluation of iron stores in blood donors by serum ferritin. 2006. 
[27]. Gardner JW, Dinsmore RC. Evolution of the concept of the febrile seizure as it developed in the American medical literature 18001980. J Hist Med Allied Sci 1995;50:340-63.

[28]. Kumari PL, Nair MKC, Nair SM, Lalitha K, Geetha S. Iron deficiency as a risk factor for simple febrile seizures - A case control study. 2001 May;30(5):1-4.

[29]. Lennox MA. Febrile convulsions in childhood: their relationship to adult epilepsy. J Pediatr 1949;35:427-35.

[30]. Livingston S, Bridge EM, Kajdi L. Febrile convulsions: a clinical study with special reference to heredity and prognosis. J Pediatr 1947;31:509-12.

[31]. Van den Berg BJ, Yerushalmy J. Studies on convulsive disorders in young children. I. Incidence of febrile and nonfebrile convulsions by age and other factors. Pediatr Res 1969;3:298-304.

[32]. Nelson KB, Ellenberg JH. Prognosis in children with febrile seizures.Pediatrics. 1978;61,720-7.

[33]. Verity CM, Golding J. Risk of epilepsy after febrile convulsions: a national cohort study. Br Med J 1985;303:1373-6.

[34]. Consensus statement on febrile seizures. In: Febrile seizures, Nelson KB, Ellenberg JH, eds. New York: Raven Press; 1981. pp. 301.

[35]. Newton C, Warrell D. Neurological manifestations of falciparum malaria. Ann Neurol 1998;43:695-702.

[36]. Shinnar S. Febrile Siezure. ed. In: Pediatric neurology; principle and practise, Swaiman K, Ashwal S, eds. St Louis: Mosby Inc; 1999. pp. 676-82.

[37]. Hauser WA, Kurland LT. The epidemiology of epilepsy in Rochester, Minnesota, 1935 through 1967. Epilepsia 1975;16:1-66.

[38]. Stanhope JM, Brody JA, Brink E. Convulsions among the Chamorro people of Guam, Mariana Islands. Part II. Febrile convulsions. Am J Epidemiol 1972; 95:299-304.

[39]. Tsai FJ, Hsieh YY, Chang CC, et al. Polymorphisms for interleukin 1 beta exon 5 and interleukin 1 receptor antagonist in Taiwanese children with febrile convulsions. Arch Pediatr Adolesc Med 2002;156:545-8.

[40]. Tsai FJ, Hsieh YY, Chang CC. Polymorphisms for interleukin 1 beta exon 5 and interleukin 1 receptor antagonist in Taiwanese children with febrile convulsions. Arch Pediatr Adolesc Med 2002;156:545-8.

[41]. Engel J Jr, Pedley TA. Epilepsy A Comprehensive text book 2nd ed. Philadelphia: Pennsylvanis, Wolters Kulver, Lippincott Williams and Wilkins; 2007. pp. 659-60.

[42]. Bethune P, Gordon K, Dooley J. Which child will have a febrile seizure? Am J Dis Child 1993;147:35-9.

[43]. Camfield P, Camfield C, Gordon K. What types of epilepsy are preceded by febrile seizures? A population-based study of children. Dev Med Child Neurol 1994;36:887-92.

[44]. Van Esch A, Steyerberg EW, Berger MY.Family history and recurrence of febrile seizures. Arch Dis Child 1994;70:395-9.

[45]. Berg AT, Shinnar S, Hauser WA. A prospective study of recurrent febrile seizures. N Engl J Med 1992;327:1122-7.

[46]. Berg AT, Shinnar S, Hauser WA. Predictors of recurrent febrile seizures: a prospective cohort study. Arch Pediatr Adol Med 1997;151:371-8.

[47]. Berg AT, Shinnar S, Hauser WA. Predictors of recurrent febrile seizures: a metaanalytic review. J Pediatr 1990;116:329-37.

[48]. Annegers JF, Hauser WA, Anderson VE. The risk of seizure disorders among relatives of patients with childhood-onset epilepsy. Neurology 1982;32:174-9.

[49]. Tsuboi T. Genetic aspects of febrile convulsions. Hum Genet 1977;38:169-73. 53. Baraitser M. Relevance of a family history of seizures. Arch Dis Child 1983; 58:404-5. 54. Dravet C, Bureau M, Oguni H. Severe myoclonic epilepsy in infancy (Dravet

[50]. syndrome). 3rd ed. In: Epileptic Syndromes in Infancy, Childhood and Adolescence, Roger J, Bureau M, Dravet C, Genton P, Tassinari CA, Wolf P, eds. Eastleigh, UK: John Libbey \& Co Ltd; 2002. pp. 81-103.

[51]. Claes L, Del-Favero J, Ceulemans B. De novo mutations in the sodium-channel gene SCN1A cause severe myoclonic epilepsy of infancy. Am J Hum Genet 2001;68:1327-32.

[52]. Hirtz DG, Nelson KB, Ellenberg JH. Seizures following childhood immunizations. J Pediatr 1983;102:14-8.

[53]. Hirtz DG, Nelson KB. The natural history of febrile seizures. Ann Rev Med 1983; 34:453-71.

[54]. Barlow WE, Davis RL, Glasser JW. The risk of seizures after receipt of wholecell pertussis or measles, mumps, and rubella vaccine.N Engl J Med. 2001; 345:656-61.

[55]. Le Saux N, Barrowman N, Moore D. Decrease in hospital admissions for febrile seizures and reports of hypotonic-hyporesponsive episodes presenting to hospital emergency departments since switching to acellular pertussis vaccine in Canada: a report from IMPACT. Pediatrics 2003;112:e348.

[56]. Kanemoto K, Kawasaki J, Yuasa S. Increased frequency of interleukin-1 beta- 511T allele in patients with temporal lobe epilepsy, hippocampal sclerosis, and prolonged febrile convulsion. Epilepsia 2003;44(6):796-99.

[57]. McCaughran JA Jr, Schechter N. Experimental febrile convulsions: long-term effects of hyperthermiainduced convulsions in the developing rat. Epilepsia 1982;23:173-83.

[58]. Tsai FJ, Hsieh YY, Chang CC. Polymorphisms for interleukin 1 beta exon 5 and interleukin 1 receptor antagonist in Taiwanese children with febrile convulsions. Arch Pediatr Adolesc Med 2002;156:545-8.

[59]. Virta M, Hurme M, Helminen M. Increased plasma levels of pro- and anti-inflammatory cytokines in patients with febrile seizures. Epilepsia 2002;43:920-3.

[60]. Hirtz DG, Nelson KB, Ellenberg JH. Seizures following childhood immunizations. J Pediatr 1983;102:14-8.

[61]. Holtzman D, Obana K, Olson J. Hyperthermia-induced seizures in the rat pup: a model for febrile convulsions in children. Science 1981;213:1034-6.

[62]. Barone SR, Kaplan MH, Krilov LR. Human herpesvirus-6 infection in children with first febrile seizures. J Pediatr 1995;127:95-7.

[63]. Suga S, Suzuki K, Ihira M. Clinical characteristics of febrile convulsions during primary HHV -6 infection. Arch Dis Child. 2000;82:62-6.

[64]. Van Zeijl JH, Mullaart RA, Borm GF. Recurrence of febrile seizures in the respiratory season is associated with influenza A. J Pediatr 2004;145:800-5.

[65]. Mody I, Pearce RA. Diversity of inhibitory neurotransmission through GABA(A) receptors. Trends Neurosci 2004;27:569-75.

[66]. Brooks-Kayal AR, Shumate MD, Jin H. Human neuronal gamma-aminobutyric acid(A) receptors: coordinated subunit mRNA expression and functional correlates in individual dentate granule cells. J Neurosci 1999;19:8312-8.

[67]. Shumate MD, Lin DD, Gibbs JW. GABA(A) receptor function in epileptic human dentate granule cells: comparison to epileptic and control rat. Epilepsy Res 1998;32:114-28.

[68]. Brooks-Kayal AR, Shumate MD, Jin H. Selective changes in single cell GABA(A) receptor subunit expression and function in temporal lobe epilepsy. Nat Med 1998;4:1166-72.

[69]. Loup F, Wieser HG, Yonekawa Y. Selective alterations in GABA 'A' receptor subtypes in human temporal lobe epilepsy. J Neurosci 2000;20:5401-19. 
[70]. Pirker S, Schwarzer C, Czech T. Increased expression of GABA(A) receptor betasubunits in the hippocampus of patients with temporal lobe epilepsy. J Neuropathol Exp Neurol 2003;62:820-34.

[71]. Cohen I, Navarro V, Clemenceau S. On the origin of interictal activity in human temporal lobeepilepsy in vitro.Science.2002; 298:1418-21.

[72]. Wozny C, Kivi A, Lehmann TN. Comment on the origin of interictal activity in human temporal lobe epilepsy in vitro. Science 2003;301:463

[73]. Patrylo PR, Spencer DD, Williamson A. GABA uptake and heterotransport are impaired in the dentate gyrus of epileptic rats and humans with temporal lobe sclerosis. J Neurophysiol 2001;85:1533-42.

[74]. Lee TS, Bjornsen LP, Paz C. GAT1 and GAT3 expression are differently localized in the human epileptogenic hippocampus. Acta Neuropathol (Berl) 2006;111:351-63.

[75]. Mathern GW, Mendoza D, Lozada A. Hippocampal GABA and glutamate transporter immunoreactivity in patients with temporal lobe epilepsy. Neurology 1999;52:453-72.

[76]. Williamson A, Telfeian AE, Spencer DD. Prolonged GABA responses in dentate granule cells in slices isolated from patients with temporal lobe sclerosis. J Neurophysiol 1995;74:378-87.

[77]. Princivalle AP, Duncan JS, Thom M. GABA(B1a), GABA(B1b) AND GABA(B2) mRNA variants expression in hippocampus resected from patients with temporal lobe epilepsy. Neuroscience 2003;122:975-84.

[78]. U.S. Preventive Services Task Force. Screening for iron deficiency anemia - including iron prophylaxis. 2nd ed. In: Guide to Clinical Preventive Services. Baltimore, Md: Williams \& Wilkins; 1996. pp. 231-46.

[79]. Iron deficiency anaemia: assessment, prevention, and control. A guide for programme managers. Geneva: World Health Organization; 2001.

[80]. National Family Health Survey (NFHS-3); 2005-06.

[81]. Andrews NC, Ullrich CK, Fleming MD. Nathan and Oski's Hematology of infancy and childhood. 7th ed. Philadelphia: Saunders Elsevier;. pp. 522-42.

[82]. Miller DR, Robert L Baehner RL.Blood diseases of infancy and childhood. Mosby; pp. 194-6.

[83]. Finch PH, Huebers HA. Iron metabolism. Clin Physiol Bio Chem 1986;4:5

[84]. Wheby MS, Jones LG, Crosby WH. Studies on iron absorption: intestinal regulatory mechanisms. J Clin Invest 1964;43:1433.

[85]. Gitlin D, Cruchaus A. on the kinetics of iron absorption in mice. J Physiol 1938; 41:344-50.

[86]. Kappas A, Drummond GS, Galbraith RA. prolonged clinical use of a heme oxygenase inhibitor:hematological evidence for an inducible but reversible iron deficiency state. Pediatrics 1993;91:537-9.

[87]. Zijp IM, Korver O, Tijburg LB. Effect of tea and other dietary factors on iron absorption. Crit Rev Food Sci Nutr 2000;40:371 -98.

[88]. Gillooly M, Bothwell TH, Charlton RW. Factors affecting the absorption of iron from cereals. Br J Nutr 1984;51:37-46.

[89]. Gillooly M, Bothwell TH, Torrance JD. The effects of organic acids, phytates and polyphenols on the absorption of iron from vegetables. Br J Nutr 1983;49:331-42.

[90]. McKie AT, Barrow D, Latunde-Dada GO. An iron-regulated ferric reductase associated with the absorption of dietary iron. Science 2001;291:1755-9.

[91]. Gunshin H, Fujiwara Y, Custodio AO. Slc11a2 is required for intestinal iron absorption and erythropoiesis but dispensable in placenta and liver. J Clin Invest 2005;115:1258-66.

[92]. Gunshin H, Mackenzie B, Berger UV. Cloning and characterization of a mammalian proton-coupled metal-ion transporter. Nature 1997;388:482-8.

[93]. Canonne-Hergaux F, Gruenheid S, Ponka P, Gros P. Cellular and subcellular localization of the Nramp2 iron transporter in the intestinal brush border and regulation by dietary iron. Blood 1999;93:4406-17.

[94]. Piomelli S. Childhood lead poisoning in the 90's. Pediatrics 1994; 93:508-10.

[95]. Abboud S, Haile DJ. A novel mammalian iron-regulated protein involved in intracellular iron metabolism. J Biol Chem 2000; 275:19906-12.

[96]. Donovan A, Lima CA, Pinkus JL. The iron exporter ferroportin/Slc40a1 is essential for iron homeostasis. Cell Metab 2005;1:191 200 .

[97]. McKie AT, Marciani P, Rolfs A. A novel duodenal iron-regulated transporter, IREG1, implicated in the basolateral transfer of iron to the circulation. Mol Cell 2000;5:299-309.

[98]. Vulpe CD, Kuo YM, Murphy TL. Hephaestin, a ceruloplasmin homologue implicated in intestinal iron transport, is defective in the sla mouse. Nat Genet 1999;21:195-9.

[99]. Qiu A, Jansen M, Sakaris A. Identification of an intestinal folate transporter and the molecular basis for hereditary folate malabsorption. Cell 2006;127:917-28.

[100]. Finch C. Regulators of iron balance in humans. Blood 1994;84:1697-702.

[101]. Nemeth E, Ganz T. Regulation of iron metabolism by hepcidin. Annu Rev Nutr 2006;26:323-42.

[102]. Nemeth E, Tuttle MS, Powelson J. Hepcidin regulates cellular iron efflux by binding to ferroportin and inducing its internalization. Science 2004;306:2090-3.

[103]. Pigeon C, Ilyin G, Courselaud B. A new mouse liver-specific gene, encoding a protein homologous to human antimicrobial peptide hepcidin, is overexpressed during iron overload. J Biol Chem 2001;276:7811-9.

[104]. Nicolas G, Chauvet C, Viatte L. The gene encoding the iron regulatory peptide hepcidin is regulated by anemia, hypoxia, and inflammation. J Clin Invest 2002; 110:1037-44.

[105]. Weinstein DA, Roy CN, Fleming MD. Inappropriate expression of hepcidin is associated with iron refractory anemia: implication s for the anemia of chronic disease. Blood 2002; 100:3776-81.

[106]. Nemeth E, Rivera S, Gabayan V. IL-6 mediates hypoferremia of inflammation by inducing the synthesis of the iron regulatory hormone hepcidin. J Clin Invest 2004; 113:1271-6.

[107]. . Verga Falzacappa MV, Vujic Spasic M, Kessler R. STAT3 mediates hepatic hepcidin expression and its inflammatory stimulation. Blood 2007;109:353-8.

[108]. Wrighting DM, Andrews NC. Interleukin-6 induces hepcidin expression through STAT3. Blood 2006;108:3204-9.

[109]. Huff RL, Hennessey TG, Austin RE. Plasma and red cell iron turnover in normal subjects and in patients having various hematopoietic disorders. J Clin Invest 1950; 29:1041-52.

[110]. Weintraub LR, Conrad ME, Crosby WH. Regulation of the intestinal absorption of iron by the rate of erythropoiesis. Br J Haematol $1965 ; 2: 432-8$.

[111]. Beutler E, Buttenweiser E. The regulation of iron absorption. I. A search for humoral factors. J Lab Clin Med 1960;55:274-80.

[112]. Finch CA, Huebers H, Eng M, Miller L. Effect of transfused reticulocytes on iron exchange. Blood 1982;59:364-9.

[113]. Jandl JH, Katz JH. The plasma-to-cell cycle of transferrin. J Clin Invest 1963;42:314-26. 
[114]. Iacopetta BJ, Rothenberger S, Kuhn LC.A role for the cytoplasmic domain in transferrin receptor sorting and coated pit formation during endocytosis. Cell 1988;54:485-9.

[115]. Klausner RD, Ashwell G, van Renswoude J. Binding of apotransferrin to K562 cells: explanation of the transferrin cycle. Proc Natl Acad Sci USA 1983; 80:2263-6.

[116]. Klausner RD, Van Renswoude J, Ashwell G. Receptor-mediated endocytosis of transferrin in K562 cells. J Biol Chem $1983 ; 258: 4715-24$.

[117]. Zak O, Trinder D, Aisen P. Primary receptor-recognition site of human transferrin is in the C-terminal lobe. J Biol Chem 1994;269:7110-4.

[118]. Huebers H, Csiba E, Huebers E, Finch CA. Molecular advantage of diferric transferrin in delivering iron to reticulocytes: a comparative study. Proc Soc Exp Biol Med 1985;179:222-6.

[119]. Huebers HA, Huebers E, Csiba E, Finch CA. Heterogeneity of the plasma iron pool: explanation of the Fletcher-Huehns phenomenon. Am J Physiol 1984;247:R280-R283.

[120]. McGraw TE, Maxfield FR: Human transferrin receptor internalization is partly dependent upon an aromatic amino acid in the cytoplasmic domain. Cell Regul 1990;1:369-77.

[121]. Miller K, Shipman M, Trowbridge IS, Hopkins CR. Transferrin receptors promote the formation of clathrin lattices. Cell $1991 ; 65: 621$.

[122]. Rothenberger S, Iacopetta BJ, Kuhn LC. Endocytosis of the transferrin receptor requires the cytoplasmic domain but not its phosphorylation site. Cell 1987; 49:423-31.

[123]. Collawn JF, Lai A, Domingo D. YTRF is the conserved internalization signal of the transferrin receptor, and a second YTRF signal at position 30-34 enhances endocytosis. J Biol Chem 1993;268:21686-92.

[124]. Dautry-Varsat A, Ciechanover A, Lodish HF. pH and the recycling of transferrin during receptor-mediated endocytosis. Proc Natl Acad Sci USA 1983;80:2258-62.

[125]. Paterson S, Armstrong NJ, Iacopetta BJ. Intravesicular $\mathrm{pH}$ and iron uptake by immature erythroid cells. J Cell Physiol 1984;120:225-32.

[126]. Van Renswoude J, Bridges KR, Harford JB, Klausner RD. Receptor-mediated endocytosis and the uptake of iron in K562 cells: Identification of a nonlysosomal acidic compartment. Proc Natl Acad Sci USA 1982;79:6186-90.

[127]. Canonne-Hergaux F, Zhang AS, Ponka P, Gros P. Characterization of the iron transporter DMT1 (NRAMP2/DCT1) in red blood cells of normal and anemic mk/mk mice. Blood 2001;98:3823-30.132. Shaw GC, Cope JJ, Li L. Mitoferrin is essential for erythroid iron assimilation. Nature 2006;440:96-100.

[128]. Klausner RD, van Renswoude J, Ashwell G. Receptor-mediated endocytosis of transferrin in K562 cells. J Biol Chem $1983 ; 258: 4715-24$.

[129]. Harrison PM, Arosio P. The ferritins: molecular properties, iron storage function and cellular regulation. Biochim Biophys Acta 1996;1275:161-203.

[130]. Levi S, Luzzago A, Cesareni G. Mechanism of ferritin iron uptake: activity of the H-chain and deletion mapping of the ferrooxidase site. A study of iron uptake and ferro-oxidase activity of human liver, recombinant $\mathrm{H}$-chain ferritins, and two $\mathrm{H}$-chain deletion mutants. J Biol Chem 1988; 263:18086-92.

[131]. Theil EC, Takagi H, Small GW. The ferritin iron entry and exit problem. Inorganica Clin Acta 1999;297:242-51.

[132]. Lanzkowsky P. Manual of Pediatric Hematology and Oncology. 4th ed. : ; 2005. pp. 33-8.138. Theil EC, Takagi H, Small GW. The ferritin iron entry and exit problem. Inorganica Clin Acta 1999;297:242-51.

[133]. Drysdale J, Jain SK, Boyd D. Human ferritins: genes and proteins. In: Spik G, Montreuil J, Crichton RR, Mazurier J, ed. Proteins of Iron Storage and Transport, New York: Elsevier; 1985:343.

[134]. McClarty G, Chan AK, Choy BK, Wright JA. Increased ferritin gene expression is associated with increased ribonucleotide reductase gene expression and the establishment of hydroxyurea resistance in mammalian cells. J Biol Chem 1990; 265:7539-7547.

[135]. Worwood M, Brook JD, Cragg SJ. Assignment of human ferritin genes to chromsomes 11 and 19q13.3-19 qter. Hum Genet 1985; 69:371-374.

[136]. Lipschitz DA, Cook JD, Finch CA. A clinical evaluation of serum ferritin as an index of iron stores. N Engl J Med 1974;290:12 13.

[137]. Elin RJ, Wolff SM, Finch CA. Effect of induced fever on serum iron and ferritin concentrations in man. Blood 1977; 49:147

[138]. Lanzkowsky P. Manual of Pediatric Hematology and Oncology. 4th ed; 2005. pp. 33-8.

[139]. Anonymous. Practice parameter: long-term treatment of the child with simple febrile seizures. American Academy of Pediatrics.Committee on Quality Improvement, Subcommittee on Febrile Seizures.Pediatrics. 1999; 103(6Pt1):1307-9.

[140]. Anonymous. Practice parameter: the neurodiagnostic evaluation of the child with a first simple febrile seizure. American Academy of Pediatrics. Provisional Committee on Quality Improvement, Subcommittee on Febrile Seizures. Pediatrics. 1996;97:769-72.

[141]. Hugan CAC, Oudesluys-Murphy Am, Hopp WCJ. Serum sodium levels and probability of recurrent febrile seizures. Eur J Pediatr $1995 ; 154: 403-5$

[142]. Kiviranta T, Airaksinen EM. Low serum sodium levels are associated with subsequent febrile seizures. Acta Ped. 1995;84:1372-4.

[143]. Thoman J, Duffner P, Shucard J. Do serum sodium levels predict recurrent febrile seizures within 24 hours? Pediatr Neurol 2004;31(5):342-4.

[144]. Green SM, Rothrock SG, Clem KJ. Can seizures be the sole manifestation of meningitis in febrile children? Pediatrics. 1993;92:527-34.

[145]. Wears RL, Luten RC, Lyons RG. Which laboratory tests should be performed on children with apparent febrile confusions: an analysis and review of the literature. Pediatr Emerg Care 1986;2:191-6.

[146]. Amir A. Kimia, Andrew J. Capraro, David Hummel, Patrick Johnston, MMath, Marvin B. Harper, Utility of Lumbar Puncture for First Simple Febrile Seizure Among Children 6 to 18 Months of Age Aap Publication 2009;123:6-12.

[147]. Offringa M, Bossuyt PMM, Lubsen J. Risk factors for seizure recurrence in children with febrile seizures: a pooled analysis of individual patient data from five studies. J Pediatr 1994;124:574-84.

[148]. Lorber J, Sunderland R. Lumbar puncture in children with convulsions associated with fever. Lancet 1980;1:785-6.

[149]. Morales A, Bass N, Lake-Smith K. Computerized tomography and febrile seizures Ann Neurol 1992;32:432.

[150]. Millichap JG, Colliver JA. Management of febrile seizures: survey of current practice and phenobarbital usage. Pediatr Neurol $1991 ; 7: 243-8$.

[151]. Sofijanov NG, Emoto S, Kuturec M, et al. Febrile seizures: clinical characteristics and initial EEG.Epilepsia 1992;33:52-7.

[152]. Rajakumar K, Bodensteiner JB. Febrile myoclonus: a survey of pediatric neurologists. Clin Pediatr 1996;22:331-2.

[153]. Lee W, Ong H. Afebrile seizures associated with minor infections: comparison with febrile seizures and unprovoked seizures. Pediatr Neurol 2004;31:157-64.

[154]. Greer JP, Foerster J, Lukens JN. Wintrobe`s clinical hematology. 11th ed. Lippincott Williams \& Wilkins Publisher 2003 Dec;794. 
[155]. Siimes MA, Addiego JE, Jr, Dallman PR. Ferritin in Serum: Diagnosis of Iron Deficiency and Iron Overload in Infants and Children Blood. 1974;43:581-90

[156]. Report of a Joint World Health Organization/Centers for Disease Control and Prevention Technical Consultation on the Assessment of iron Status at the Population Level Geneva, Switzerland. Assessing the Iron status of populations; 2004 Apr.

[157]. US Preventive Services Task Force. Screening for iron deficiency anemia - including iron prophylaxis. In: Guide to Clinical Preventive Services. 2nd ed. Baltimore, Md: Williams \& Wilkins, 1996:231-46.

[158]. Cook JD, Flowers CH, Skikne BS. The quantitative assessment of body iron Blood. 2002;10:3071.

[159]. Killip S, Bennett JM, Chambers MD. Iron deficiency anemia. Am Fam Physician 2007;75:671-8.

[160]. Guyatt GH, Oxman AD, Ali M, Willan A, McIlroy W, Patterson C. Laboratory diagnosis of iron-deficiency anemia: an overview. J Gen Intern Med 1992 Mar-Apr;7(2):145-53.

[161]. Kis AM,Carnes M. Detecting iron deficiency in anemic patients with concomitant medical problems. J Gen Intern Med 1998 Jul;13(7):455-61.

[162]. Killip S, Bennett JM, Chambers MD. Iron deficiency anemia. AM Fam Physician 2007;75:671-8.

[163]. Hirtz DG, Lee YJ, Ellenberg J. Survey on the management of febrile seizures. Am J Dis Child 1986;140:909.

[164]. Millichap JG. Management of febrile seizures: current concepts and recommendation for phenols arbital and the electro encephalogram. Clin Electroencephalogram 1991;22:5.

[165]. American Academy of Pediatrics. Practice parameter: Long-term treatment of the child with simple febrile seizures. Pediatrics; 1999;103:1307.

[166]. Knuden FU. Practical management to simple and complex febrile seizures. San Diego: Academic Press; 2002.

[167]. Dodson WE, DeLorenzo RJ, Pedley TA. The treatment of convulsive status epilepticus: Recommendations of the epilepsy foundation of America's working group on status epilepticus. JAMA 1993;270:854.

[168]. Maytal J, Shinnar S. Status epilepticus. In: Childhood seizures, Shinnar S, Amir N, Branski D, eds. Basel, Switzerland: Karger S; 1995.

[169]. Anthony J, Hawke S. Phenobarbitral compared with carbamazepine in prevention of recurrent febrile convulsion. Am J Dis Child $1983 ; 137: 892$.

[170]. Bacon C, Mucklow J, Rawlins M. Placebo-controlled study of phenobarbitose and phenytoin in the prophylaxis of febrile convulsions. Lancet 1981;11:600.

[171]. Guzman AR, Castillejos EL, Vicuña WL, Laguia VL, Balarezo W, Gurreoner RL. Anemia: a possible risk factor for the first febrile seizure. Paediatrica $2005 ; 7(2): 62-5$.

[172]. Sherjil A, Zaheer-Us-Saeed, Shehzad S, Amjad R. Iron deficiency anaemia - a risk factor for febrile seizures in children. J Ayub Med Coll Abbottabad 2010;22(3).

[173]. Dr.R.Ganesh,Lalitha Janakiraman. Serum Zinc levels in simple febrile seizures. CLIN PEDIATR March 2008 47: 164-166,first published on September 14, 2007.

[174]. Izumi Y, Ishii K, Akiba K, Hayashi T. Hypozincemia during fever may trigger febrile convulsion. Med Hypotheses. 1990 May; 32(1):77-80.

[175]. Burhanoglu M, Tutuncuoglu s, Coker C, et al. Hypozincemia in febrile convulsion. Eur J Pediatr. 1996;155(6):498-501.

[176]. MayharA, PahlavanA.A,Varasteh Nejad A.Serum Zinc level in children with febrile seizures.Acta Medica Iranica.2008;46( 6 ):476480

[177]. Fahimch Ehsanipour, Mahshid Talibi Taher, Nahid Vahid Harandi et al. Serum Zinc level in children with febrile convulsion and its comparison with that of control group.Iran J Pediatr. 2009;19 ( 1) :65-68.

[178]. Mojtabaamiri et al. Serum trace element levels in febrile convulsions. Biological Trace Element Research- Vol135,No1-3,pg38-44 july 2009.

[179]. Modarresi MR,Shahkarami SMA, Yaghini O, Shahbi J, Mosaiiebi D, Mahmoodian T. The relationship between Zinc deficiency and Febrile Convulsion in Isfahan,Iran. Iranian Journal of Child Neurology 2011 Spring;5(2):27-31. 